Research Article

\title{
Shaking Table Study on the Seismic Performance of Geogrid Reinforced Soil Retaining Walls
}

\author{
Xiaoguang Cai $\mathbb{D}^{1,2,3}$ Sihan Li $\mathbb{C}^{1,2,3}$ Honglu Xu $\mathbb{D}^{4},{ }^{4}$ Liping Jing $\mathbb{D}^{1,4}$ Xin Huang $\mathbb{D}^{1,2,3,4}$ \\ and Chen $Z_{\text {hu }}{ }^{5}$ \\ ${ }^{1}$ College of Geological Engineering, Institute of Disaster Prevention, Sanhe 065201, China \\ ${ }^{2}$ Hebei Key Laboratory of Earthquake Disaster Prevention and Risk Assessment, Sanhe 065201, China \\ ${ }^{3}$ Key Laboratory of Building Collapse Mechanism and Disaster Prevention, China Earthquake Administration, \\ Sanhe 065201, China \\ ${ }^{4}$ Key Laboratory of Earthquake Engineering and Engineering Vibration, Institute of Engineering Mechanics, \\ China Earthquake Administration, Harbin 150080, China \\ ${ }^{5}$ School of Civil and Transportation Engineering, Hebei University of Technology, Tianjin 300401, China
}

Correspondence should be addressed to Sihan Li; lisihan@st.cidp.edu.cn

Received 1 December 2020; Revised 19 May 2021; Accepted 1 June 2021; Published 24 June 2021

Academic Editor: Salvatore Grasso

Copyright $\odot 2021$ Xiaoguang Cai et al. This is an open access article distributed under the Creative Commons Attribution License, which permits unrestricted use, distribution, and reproduction in any medium, provided the original work is properly cited.

This study presents experimental results from shaking table tests on a reduced-scale geogrid reinforced soil retaining wall (RSRW) to investigate the seismic response of the fundamental frequency, acceleration amplification, face displacement, backfill surface settlement, and reinforcement strain under different peak accelerations and durations. The fundamental frequency is in good agreement with the predicted values. The root mean square (RMS) acceleration amplification factors increase nonlinearly with the wall height and decrease with increasing seismic load, which is not regarded as a constant value. The distributions of the peak displacement are consistent with those of the residual displacement. The combination of the sliding and rotation is observed as the predominant mode of displacement, and the rotation mode is dominant. The positions near the face $(35 \mathrm{~cm})$ and the ends of the reinforcement $(140 \mathrm{~cm})$ demonstrated larger settlement than that of the central position $(70 \mathrm{~cm}$ and $105 \mathrm{~cm})$. The reinforcement strain increased with increasing peak acceleration and maximum values measured at the central layers. The trends of the potential failure surface are similar to those of the $0.3 \mathrm{H}$ bilinear failure surface. The friction coefficient is nonlinearly distributed along with the reinforcements, and the maximum friction coefficient appears at the top layer (F11).

\section{Introduction}

A large number of geosynthetic reinforced soil retaining walls (RSRWs) have been used in highways and industrial, military, commercial, and residential areas owing to their many merits in terms of costs, performance, aesthetics, and durability in recent years [1-3]. The excellent seismic performance offered by RSRWs has been demonstrated in active earthquake areas [4-6]. However, several RSRWs failed during earthquakes, causing great losses of life and property as well as disrupting traffic [7]. Koseki et al. [8] reviewed the local instability of the segmental-type wall during the ChiChi earthquake, which was attributed to poor quality backfill and excessive reinforcement spacing. Rollins et al. [9] reported a collapsed RSRW owing to reinforcement corrosion in the Chile 8.2 earthquake in April of 2014. Yazdandoust [2] presented a summary of the deformation modes of overturning or bulging in different projects due to insufficient reinforcement length, large reinforcement spacing, and insufficient compaction of the backfill spacing length during the earthquakes in Chi-Chi, Taiwan, El Salvador, and Nisqually, USA. Consequently, the seismic design of geosynthetic reinforced soil (GRS) structures is an important issue in countries that experience earthquakes, and a seismic design procedure that is better than the old-fashioned Mononobe-Okabe pseudostatic analysis is required [10]. It is 
essential to comprehensively understand the seismic behavior of RSRWs.

The seismic behavior of RSRWs has been investigated by different researchers through postearthquake investigations, model tests, and numerical simulations. Postearthquake investigation is a direct method and a reliable approach for understanding the seismic behavior of RSRWs [4-6, 8, 11]. This is also an important basis for verifying existing theories, standards, test methods, construction methods, and operation services. However, taking into account the suddenness and uncertainty of the earthquakes, it is insufficient to understand the seismic behavior of RSRWs depending only on the data obtained from postearthquake investigations. As a result, model tests and numerical simulations have attracted widespread attention due to their repeatability and short test periods. Full-scale model tests [12-14], reducedscale model tests [2, 15-25], and numerical simulations [26-30] have mainly been performed to analyze the influence of panel form (modular-block type, full-height rigid, and wrapped), reinforcement type (strip, geogrid, and geotextile), reinforcement properties (stiffness, length, and spacing), soil properties (relative density, water content, and gradation), foundation conditions (rigid and flexible), and earthquake motion (intensity, near-field, far-field, unidirectional, and bidirectional) on the seismic response (acceleration amplification factor, fundamental frequency, dynamic earth pressure, deformation mode, and tensile load) of RSRWs.

Some people regard a reinforced soil structure as an isolated structure due to its bearing capacity, isolation characteristics, recovered function, and energy dissipation behavior [31]. It is unclear whether the RSRW can reduce the impact of an earthquake by preventing resonance. In the pseudostatic design method, the RSRW is regarded as a rigid body subjected to one acceleration value. Whether the acceleration is a constant value at different elevations in the reinforced zone needs to be studied. The deformation mode, sliding percentage, and rotation percentage under the combined action of multiple deformation modes need to be studied. Additionally, there are no relevant regulations on the failure surface under earthquake motion. It is necessary to investigate whether the linear failure surface and $0.3 \mathrm{H}$ bilinear failure surface [32] distinguish the active zone and the resistant zone that can be applied under seismic waves.

In this study, a geogrid RSRW with a modular-block face is built and tested using a large $1 \mathrm{~g}$ shaking table test. The peak acceleration of excitation is varied to examine the effects on the seismic response and the working mechanism of the RSRW. The quantitative and qualitative response of the RSRW to base shaking in terms of the fundamental frequency, acceleration amplification, face displacement, backfill surface settlement, and reinforcement strains are identified and presented.

\section{Test Program}

2.1. General. Considering that the boundary influences of the model response were not significant between rigid and laminar boxes [33], the model specimen in this study was built in a $3.00 \mathrm{~m}(L) \times 1.50 \mathrm{~m}(\mathrm{~W}) \times 2.00 \mathrm{~m}(\mathrm{H})$ rigid box. Additionally, parts of the side of the model box were made of acrylic material; it is easy to observe the experimental process and take photos because of transparency of the material. The type of box on the shaking table is consistent with that used in many studies $[2,7,16,34]$. To minimize the reflection waves from the rigid boundary, a $50 \mathrm{~mm}$ thick block of the sponge was placed at the back of the soil inside the rigid box.

One of the most effective methods for understanding the seismic performance of practical RSRWs is the use of reduced-scale specimens. A $1 \mathrm{~g}$ specimen of a modular-block RSRW is constructed at the Civil Engineering Test Center of the Institute of Disaster Prevention. Figure 1 shows the rigid box and shaking table of the specimen. The relevant technical specifications of the shaking table are given in Table 1. Within the specimen, the reinforcement length and vertical spacing are $1.26 \mathrm{~m}$ and $0.15 \mathrm{~m}$, respectively. The $1.8 \mathrm{~m}$ high specimens are designed by the scaling laws proposed by Iai [35], which are the same as those used by many studies $[19,24]$, as given in Table 2 . Scaling factors of $1 / 2$ and $1 / 4$ (model/prototype) are used, and the test on the specimens can be used to investigate the seismic performance of a $3.6 \mathrm{~m}$ high RSRW and 7.2 $\mathrm{m}$ high RSRW in the field, respectively.

Figure 2(a) shows a cross-section of the modular-block specimen. Figure 2(b) shows the entire reduced-scale geogrid RSRW during the test, and this type of RSRW has widely been applied in China and the USA (Figures 2(c) and 2(d)). Additionally, Figure 2(a) shows the instrumentation layout for the specimen. To measure the deformations, accelerations, and strain distributions of the specimen, 16 displacement meters (mandril sensors), 12 acceleration meters, and 88 strain gauges were installed in the specimen. Among them, 12 displacement meters were attached to a vertical iron column to measure the lateral displacement of the wall, 4 displacement meters were mounted on a horizontal iron column to measure the settlement of the top backfill, 6 acceleration meters were embedded in the reinforced zone of the backfill, and six other acceleration meters were embedded in the retained zone to measure the acceleration at different locations; 88 strain gauges were bonded to each geogrid layer, the strain gauges were bonded to the top and bottom in the $F 1, F 2$, and F3 layers, and the four measured points are away from the panel in the $F 5, F 6$, and $F 7$ layers to correct for bending [36]. In addition, two acceleration sensors were attached to the rigid box to measure the input acceleration.

To further understand the seismic performance of the modular-block RSRW, two seismic waves are applied in the shaking table test: one seismic wave is applied at Wolong station (WL wave) during the Wenchuan earthquake in China in 2008, and the other seismic wave is applied at El Centro station (EL wave) during the Imperial Valley earthquake in the USA in 1940. One-way lateral earthquake motion is inputted during the test after processing and normalization. The acceleration time histories and Fourier spectra for the normalized and scaled seismic motions are shown in Figure 3. To acquire the seismic parameters of the specimen, white noise is inputted before and after each 


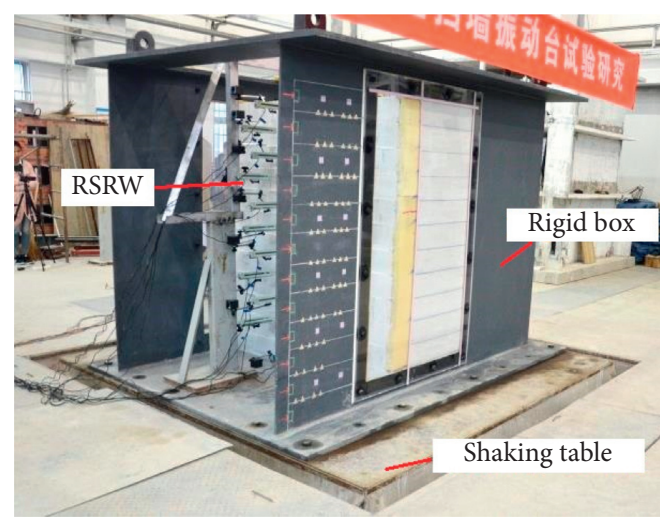

FIGURE 1: Rigid box and shaking table.

TABLE 1: Technical specifications.

\begin{tabular}{lc}
\hline Specifications & Reference values \\
\hline Size & $3.0 \mathrm{~m} \times 3.0 \mathrm{~m}$ \\
Mode & Sine, random, earthquake vibration \\
Frequency & $0.4-80 \mathrm{~Hz}$ \\
Load capacity & $20 \mathrm{t}$ \\
Antioverturning moment & $400 \mathrm{kN} \mathrm{m}$ \\
Maximum acceleration & No load: $4.5 \mathrm{~g}(X), 3.5 \mathrm{~g}(Y)$ \\
Maximum velocity & Fully load: $2.0 \mathrm{~g}(X), 2.0 \mathrm{~g}(Y)$ \\
Maximum displacement & $80 \mathrm{~cm} / \mathrm{s}(X), 70 \mathrm{~cm} / \mathrm{s}(Y)$ \\
\hline
\end{tabular}

change in wave magnitude. Although repeated seismic loading changes the initial state of the model, repeated loading can obtain more information from the specimen, which is similar to the types of inputted seismic loading that have been used for many shaking table testing programs $[2,19,24]$. The loading cases are given in Table 3 .

2.2. Materials. In this study, the grain size distribution curve of the backfill is shown in Figure 4, and the backfill is medium sand $(\mathrm{D} 10=0.18 \mathrm{~mm}, \quad \mathrm{D} 30=0.29 \mathrm{~mm}$, $\mathrm{D} 60=0.37 \mathrm{~mm}, \mathrm{Gs}=2.86, \mathrm{Cu}=2.055$, and $\mathrm{Cc}=1.262$ ), which is classified as poorly graded sand according to the Unified Soil Classification System (USCS). A maximum dry density of $1.99 \mathrm{~g} / \mathrm{cm}^{3}$ and minimum dry density of $1.52 \mathrm{~g} /$ $\mathrm{cm}^{3}$ were obtained through relative density tests. The dry density was $1.82 \mathrm{~g} / \mathrm{cm}^{3}$ to achieve a relative density of $70 \%$. Moreover, unconsolidated undrained tests and consolidated undrained tests are performed at a moisture content of $9.3 \%$, and it is evident that the sand has friction angles of $41^{\circ}$ and $37^{\circ}$, respectively. To strictly control the relative density, the backfill is layered and filled; the specific calculation method is as follows: first, the soil must be dry, and the volume weight can be obtained according to the maximum and minimum volume weight and relative density; second, the soil weight of each layer can be determined based on the volume weight and the volume of each layer; finally, it is necessary to compact the soil with compaction tools to meet the corresponding height. The methods are consistent with the methods used by Wang et al. [20].
A uniaxial high-density polyethene (HDPE) geogrid (Xuyu EG50\#, Qingdao, China) is used as the soil reinforcement. The length of the stretching unit is $22.5 \mathrm{~cm}$. The rib spacing width is $2.22 \mathrm{~cm}$. The rib thickness is $0.1 \mathrm{~cm}$. Tensile tests are performed on multirib specimens at a strain rate of $10 \% / \mathrm{min}$, according to ASTM D6637 [37]. The results indicate that the geogrid has a tensile strength of $T_{2 \%}=17.4 \mathrm{kN} / \mathrm{m}$ at $2 \%$ strain and ultimate strength of $T_{\mathrm{ult}}=50 \mathrm{kN} / \mathrm{m}$ in the machine direction. The same reinforcement was used in the reduced-scale model, and the stiffness of the geogrid in the prototype would be 16 and 4 times that in the model scaled by $1 / 4$ and $1 / 2$, respectively. The stiffness of the prototype geogrid is within the range of values for actual geosynthetic reinforcement products on the market today $[25,38]$.

As an important component of the specimen, concrete modular blocks are adopted in this study. Concerning the test results of Guler and Selek [19], the model scale of the block did not affect the maximum acceleration measured on the wall. Therefore, the modular blocks used in the field engineering are selected to be $15 \mathrm{~cm}(W) \times 25 \mathrm{~cm}$ (or $12.5 \mathrm{~cm})(L) \times 15 \mathrm{~cm}(\mathrm{H})$, as shown in Figure 5 . The fixed connection between the geogrid and modular block is realized by a plastic clasp, as shown in Figure 6 .

\section{Results}

3.1. Fundamental Frequency. As a main parameter of RSRWs, the fundamental frequency (FF) is the key to determining whether resonance phenomena occur under actual earthquakes. In shaking table tests, white noise can be input to obtain the FF of the reduced-scale specimen. Yazdandoust [2] used two methods to calculate the FF based on impact pulse tests: the first method is $\mathrm{FF}=V_{\mathrm{s}} / 4 \mathrm{H}$, where $V_{\mathrm{s}}$ is the shear wave velocity of the RSRW, and $\mathrm{H}$ is the wall height; the second method uses spectral analysis of the free vibration response after the impact pulse. Richardson and Lee [25] predicted the FF of a RSRW based on the equation $\mathrm{FF}=1 /(\mathrm{HC})$, where $\mathrm{H}$ is the wall height, and $\mathrm{C}$ is a coefficient that varies between 0.02 and 0.033 . The predicted result shows that the FF is between 16.83 and $27.78 \mathrm{~Hz}$. Using white noise motion before specimen tests to obtain the free vibration Fourier spectra is shown in Figure 7. The results shows that the FF is $22.7 \mathrm{~Hz}$, which is within the range of the predicted results of Richardson and Lee.

The code for seismic design of buildings [39] stipulates that the four categories of site periods are between $0.20 \mathrm{~s}$ and $0.90 \mathrm{~s}$, and the fundamental site frequency is between $1.11 \mathrm{~Hz}$ and $5.00 \mathrm{~Hz}$. Seismic isolation technology of the structure prevents site-structure resonance by changing the FF of the structure. Based on the concept described above, $H<V_{s} / 20$ [2] or $H<6$ (Richardson and Lee method) is needed to prevent resonance between the RSRW and the site. The results of postearthquake investigations proved that the seismic performance of the RSRW is sufficient. Thus, resonance is not a key factor affecting the seismic performance of RSRW, and it is essential to find the causes from the RSRW itself. 
TABLE 2: Scaling factors in the specimen.

\begin{tabular}{|c|c|c|c|c|}
\hline \multirow[t]{2}{*}{ Number } & \multirow[t]{2}{*}{ Physical quantity } & \multirow[t]{2}{*}{ Similarity constants } & \multicolumn{2}{|c|}{$\begin{array}{l}\text { Scaling factor (prototype/ } \\
\text { model) }\end{array}$} \\
\hline & & & $2: 1$ & $4: 1$ \\
\hline 1 & Length $(L)$ & $C_{L}$ & 2 & 4 \\
\hline 2 & Elastic modulus $(E)$ & $C_{E}=1$ & 1 & 1 \\
\hline 3 & Density $(\rho)$ & $C_{\rho}=1$ & 1 & 1 \\
\hline 4 & Stress $(\sigma)$ & $C_{\sigma}=C_{E}=1$ & 1 & 1 \\
\hline 5 & Time $(t)$ & $C_{t}=C_{L}^{0.5}$ & 1.414 & 2 \\
\hline 6 & Velocity $(v)$ & $C_{\mathrm{v}}=C_{L}^{0.5}$ & 1.414 & 2 \\
\hline 7 & Acceleration $(a)$ & $C_{\mathrm{a}}=1$ & 1 & 1 \\
\hline 8 & Gravity $(g)$ & $C_{\mathrm{g}}=1$ & 1 & 1 \\
\hline 9 & Frequency $(\omega)$ & $C_{\omega}=C_{L}^{-0.5}$ & 0.707 & 0.5 \\
\hline
\end{tabular}

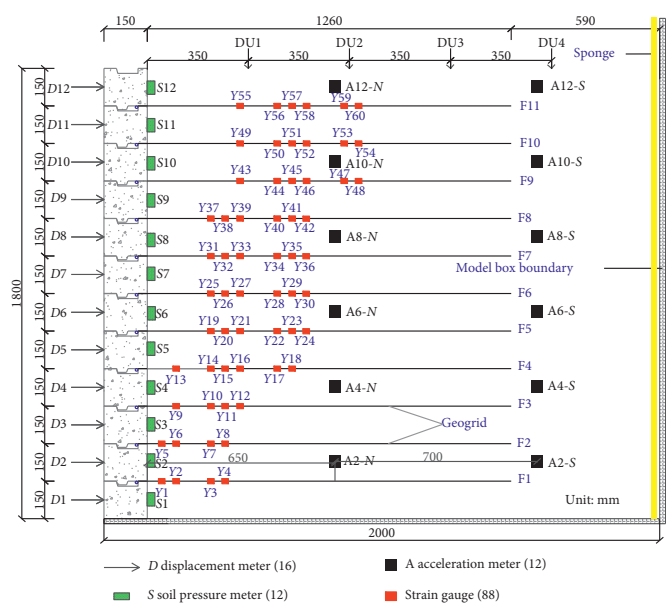

(a)

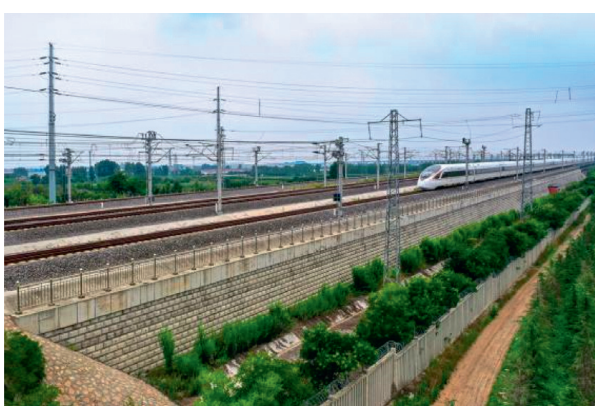

(c)

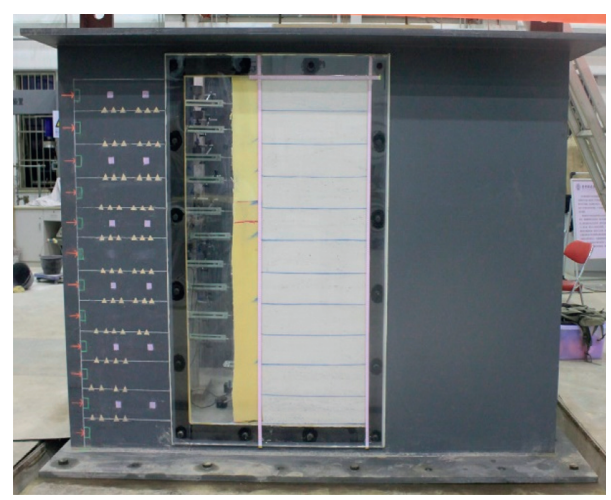

(b)

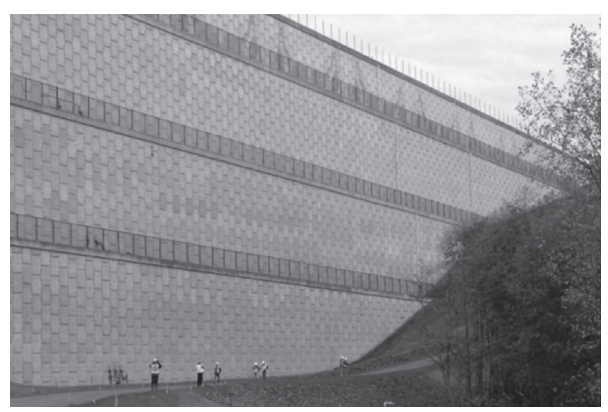

(d)

Figure 2: Modular-block specimens: (a) specimen, (b) reduced-scale geogrid RSRW, (c) Qingrong railway (CTAG, 2019), and (d) SeaTac airport runway (FHWA, 2009).

3.2. Acceleration Amplification. The determination of the maximum accelerations and average peak ground acceleration [32, 40-42] is essential when calculating the external stability of the seismic design. In the current study, the acceleration amplification of the RSRW is calculated based on the acceleration time history for two methods. In the first method, the acceleration amplification factors are calculated by dividing the peak acceleration measured during shaking at different elevations of the specimen based on the peak shaking table acceleration $[19,22,43]$. In the second method, the acceleration amplification factors are calculated using the root mean square (RMS) $[2,15,24]$. Equation (1) is used to calculate the RMS value $[2,15]$ :

$$
\mathrm{RMS}=\left[\frac{1}{t_{d}} \int_{0}^{t_{d}} a(t)^{2} \mathrm{~d} t\right]^{(1 / 2)},
$$

where $t_{d}$ is the duration of the acceleration record and $a(t)$ is the acceleration time history. The calculation method of the RMS acceleration amplification factor is consistent with that of the first method. The second method is selected in the 


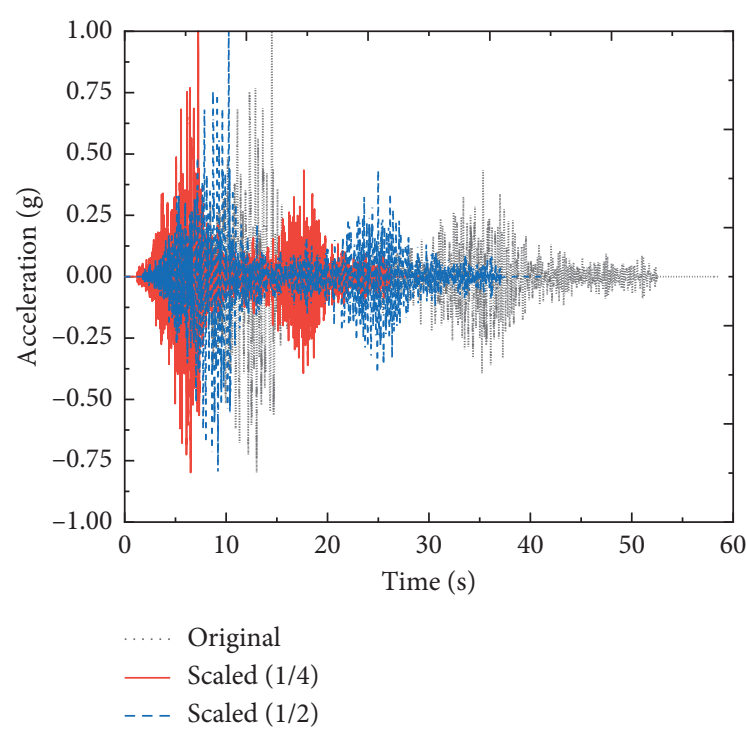

(a)

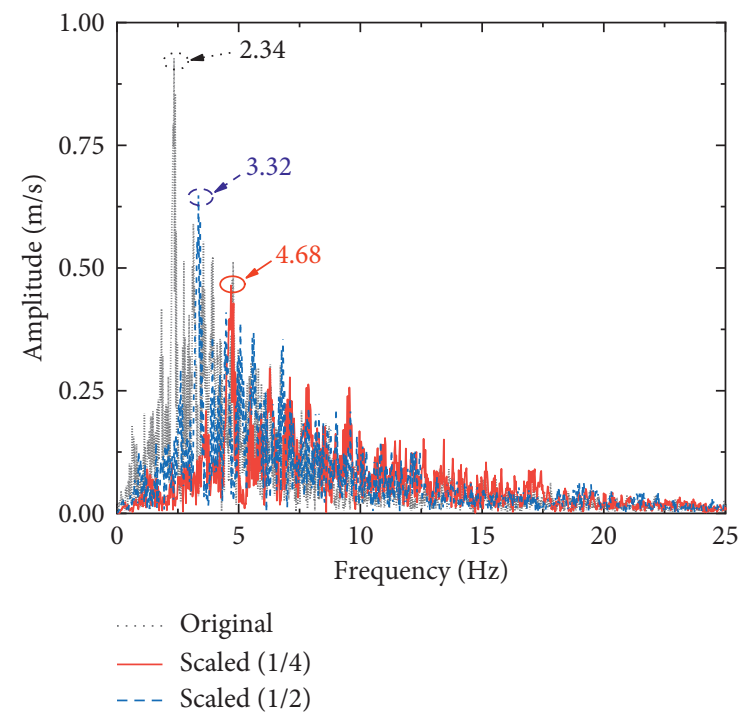

(c)

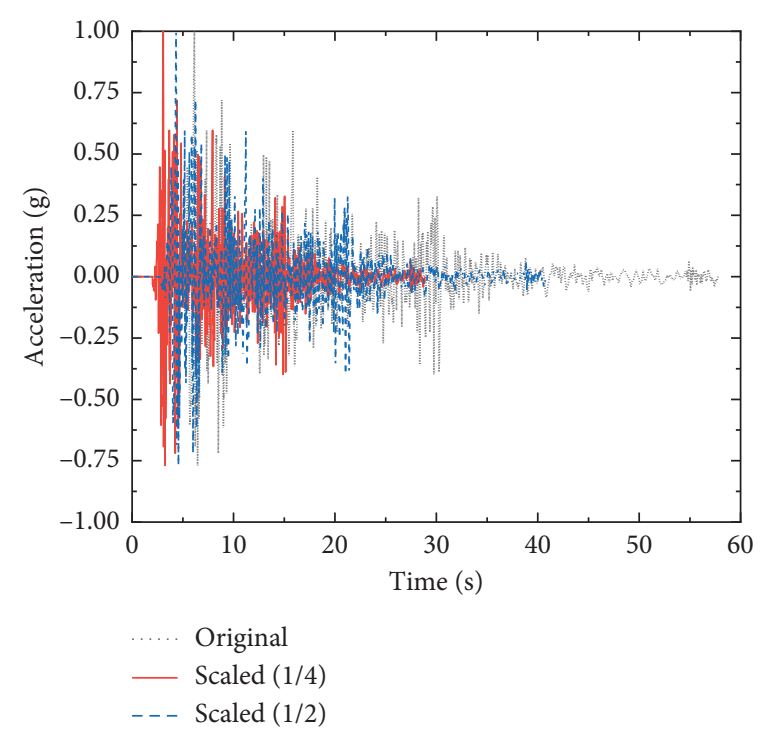

(b)

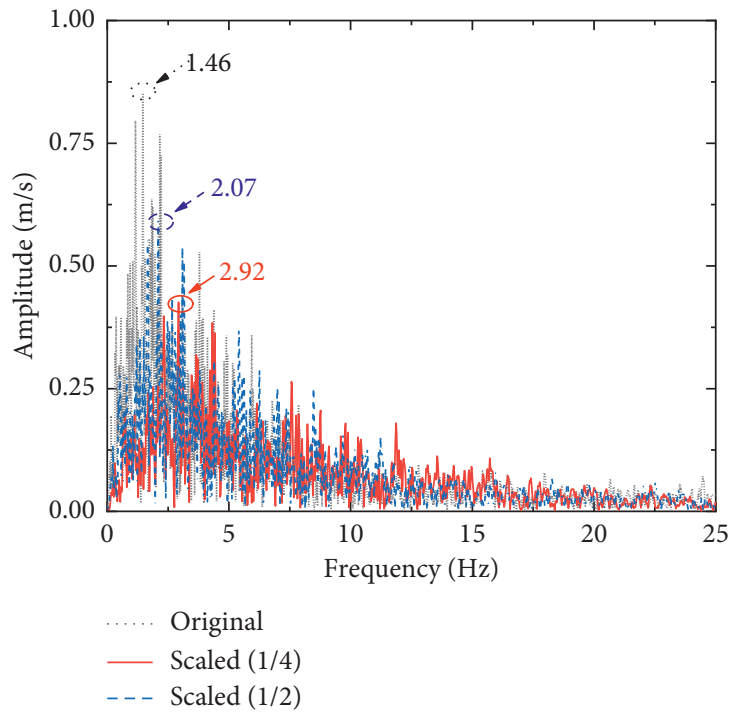

(d)

FIgURE 3: Input motions: (a) WL acceleration time history, (b) EL acceleration time history, (c) WL Fourier spectra, and (d) EL Fourier spectra.

manuscript to calculate the acceleration amplification factors. Vertical distributions of the RMS amplification factor within the reinforced zone $(x=0.65 \mathrm{~m})$ for the specimen are shown in Figures 8 and 9. The figures show that the reinforced zone of the RSRW is amplified during the various tests with different scale factors and different earthquake waves. The amplification factors are nonlinear along the wall height. The amplification factors reach a maximum value on top of the wall. The data also show that the amplification factors decrease with increasing magnitude of peak acceleration in all the tests, which is similar to the conclusion for two-tiered RSRWs obtained by Cai et al. [22]. As shown in Figures 8 and 9 , the range of the amplification factors is $1.58-1.70$ and $1.45-1.64$ under WL waves and EL waves, respectively (scale factor: $1 / 4$ ). The range of the maximum amplification factors is $1.47-1.56$ and $1.41-1.52$ under WL waves and EL waves (scale factor: 1/2), respectively. Based on the comparisons of the amplification factors with different scale factors, the different scale factors have a certain effect on the amplification factors.

A few specifications stipulate the value of the acceleration amplification factor. FHWA [32] recommends the following equation as the wall height-dependent reduction factor.

$$
\alpha=1+0.01 H\left[0.5\left(\frac{F_{v} S_{1}}{k_{\max }}\right)-1\right],
$$

where $H$ is the wall height in feet at the wall face, $F_{v}$ is the site factor, $S_{1}$ is the spectral acceleration at a period of $1 \mathrm{~s}$, and the 
TABLE 3: Loading cases.

\begin{tabular}{|c|c|c|c|c|}
\hline Case number & Input wave & PGA (g) & Model scale & Case code \\
\hline 1,2 & WL, EL & 0.1 & 4 & $\begin{array}{l}\text { WL0.1 g, } \\
\text { EL0.1 g }\end{array}$ \\
\hline 3,4 & WL, EL & 0.1 & 2 & $\begin{array}{l}\text { WL0.1 g, } \\
\text { EL0.1 g }\end{array}$ \\
\hline 5,6 & WL, EL & 0.2 & 4 & $\begin{array}{l}\text { WL0.2 g, } \\
\text { EL0.2 g }\end{array}$ \\
\hline 7,8 & WL, EL & 0.2 & 2 & $\begin{array}{l}\text { WL0.2 g, } \\
\text { EL0.2 g }\end{array}$ \\
\hline 9,10 & WL, EL & 0.4 & 4 & $\begin{array}{l}\text { WL0.4 g, } \\
\text { EL0.4 g }\end{array}$ \\
\hline 11,12 & WL, EL & 0.4 & 2 & $\begin{array}{l}\text { WL0.4 g, } \\
\text { EL0.4 g }\end{array}$ \\
\hline 13,14 & WL, EL & 0.6 & 4 & $\begin{array}{l}\text { WL0.6g, } \\
\text { EL0.6 g }\end{array}$ \\
\hline 15,16 & WL, EL & 0.6 & 2 & $\begin{array}{l}\text { WL0.6g, } \\
\text { EL0.6 g }\end{array}$ \\
\hline 17,18 & WL, EL & 0.8 & 4 & $\begin{array}{l}\text { WL0.8 g, } \\
\text { EL0.8 g }\end{array}$ \\
\hline 19,20 & WL, EL & 0.8 & 2 & $\begin{array}{c}\text { WL0.8 g, } \\
\text { EL0.8 g }\end{array}$ \\
\hline 21,22 & WL, EL & 1.0 & 4 & $\begin{array}{l}\text { WL1.0 g, } \\
\text { EL1.0 g }\end{array}$ \\
\hline 23,24 & WL, EL & 1.0 & 2 & $\begin{array}{c}\text { WL1.0 g, } \\
\text { EL1.0 g }\end{array}$ \\
\hline
\end{tabular}

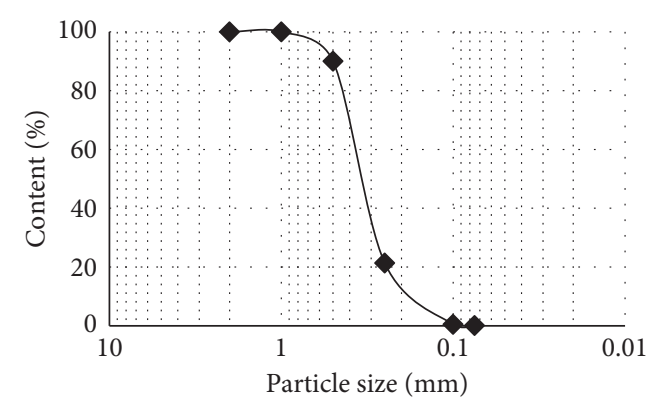

FIgURE 4: Grain size distribution curve.

$k_{\max }$ is the maximum acceleration. However, walls less than $20 \mathrm{ft}$ in height are practical, and the reduction factor is approximately 1 . The clause of the Chinese code for seismic design of railway engineering [44] (railway code) is similar to that applied in FHWA [32]; when the wall height is less than $12 \mathrm{~m}$, the factor is 1 . In addition, the wall height of a single-step RSRW is usually less than $12 \mathrm{~m}$ in the field in China. In summary, a few specifications regard the acceleration amplification factor as a constant factor $[2,15]$.

The data in Figures 8 and 9 show that there is no acceleration amplification constant mentioned above in a few specifications. Thus, the calculation result is not consistent with the actual seismic response since the nonlinear amplification factor in the reinforced zone of the RSRW is not considered.
3.3. Face Displacement. The lateral displacements during the peak acceleration (P) and at the end of shaking (residual displacement (R)) under different scale factors are shown in Figures 10 and 11. The data present similar trends between the peak displacement and residual displacement for different scale factors, with displacements nonlinearly increasing with wall height and maximum values measured at the top of the specimen. The maximum displacement values during shaking are partially recovered when shaking stops. When an earthquake does not exceed $0.4 \mathrm{~g}$, the residual displacements are slightly smaller than the peak displacement, and the peak displacements experience minimal recovery. When the earthquake exceeds $0.4 \mathrm{~g}$, the residual displacements are much less than the peak displacement, and most of the peak displacements are recovered after the earthquake. Additionally, the figure also shows that the displacement mode is the sliding toe model [15], which combines sliding and rotation, as shown in Figure 12. The lateral residual displacement at the bottom and the top of the specimen face are represented by $D_{B}$ and $D_{T}$, respectively. $\left(\mathrm{D}_{T}-\mathrm{D}_{B}\right) / D_{T}$ and $D_{B} / D_{T}$ are defined as the rotation percentage and sliding percentage in the sliding mode, respectively.

The sliding percentage and rotation percentage of the face under different earthquake motions and different loading cases are compared in Figure 13. The data show clear trends and similar trends under different scale factors. The sliding percentage decreases and the rotation percentage increases as the input acceleration increases, and the rotation percentage dominates the displacement mode of the specimen when the input acceleration exceeds $0.4 \mathrm{~g}$. However, the opposite conclusion is reported by El-Emam and Bathurst [15], who concluded that base sliding becomes the dominant wall deformation mode at a peak acceleration larger than the critical acceleration, and rotation is predominant at a peak acceleration before the critical acceleration. This is because the slide rails are applied to the bottom of the face for the test; the slide rails allow lateral sliding to easily occur for the specimen.

An understanding of the displacement mode of the RSRWs under earthquake motion is one of the key steps of the performance-based design method. Additionally, many experts [2, 45-47] have mentioned the importance of the damage grades of RSRWs, which provides the judgment basis for emergency rescue and postearthquake repair. Based on various methods, such as model tests and postearthquake investigations, classification indexes for the damage grades are proposed. Huang et al. [47] recommended 2\% (the lateral displacement to wall height ratio) and $5 \%$ as the permissible displacement and catastrophic failure displacement in cohesionless backfill, respectively. Zhang et al. [46] proposed using $0.5 \%, 3 \%$, and $6 \%$ as the displacement-controlling criterion of intact, repairable, and damaged gravity retaining walls. Yazdandoust [2] observed the seismic performance of steel-strip RSRWs and concluded that two consistent ranges 


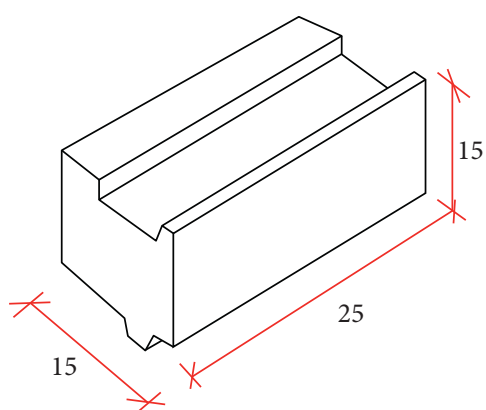

(a)

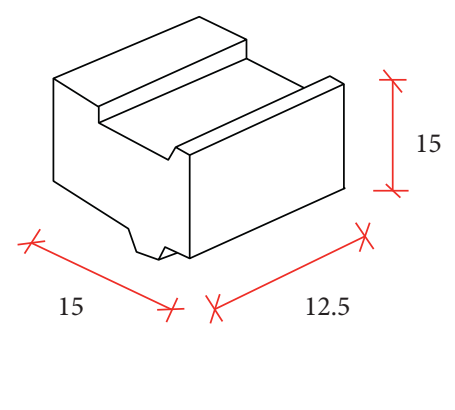

(b)

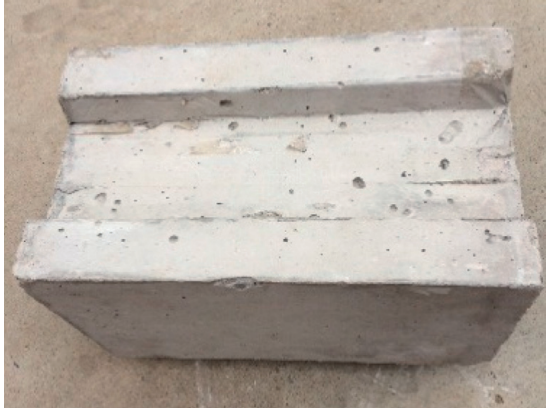

(c)

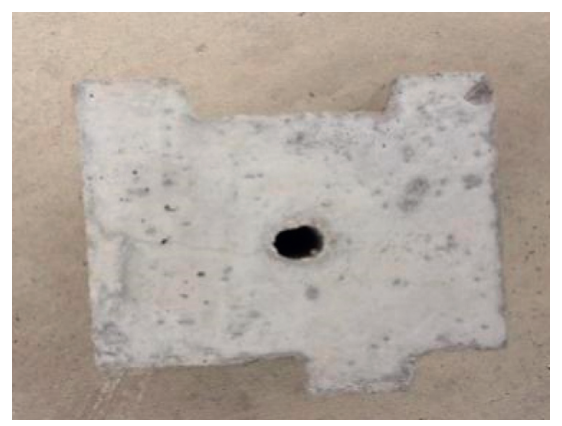

(d)

Figure 5: Modular block: (a) block sample 1, (b) block sample 2, (c) block front, and (d) block side.

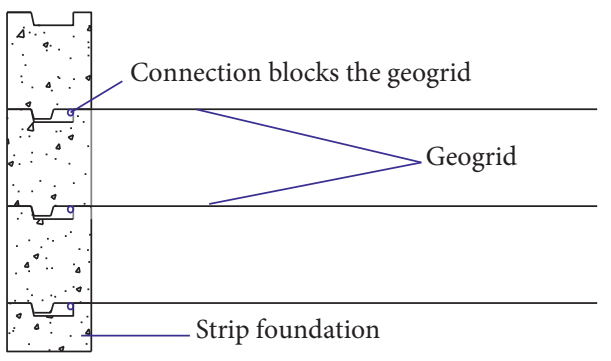

(a)

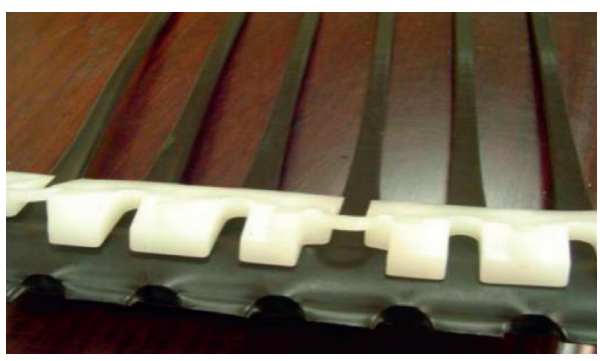

(c)

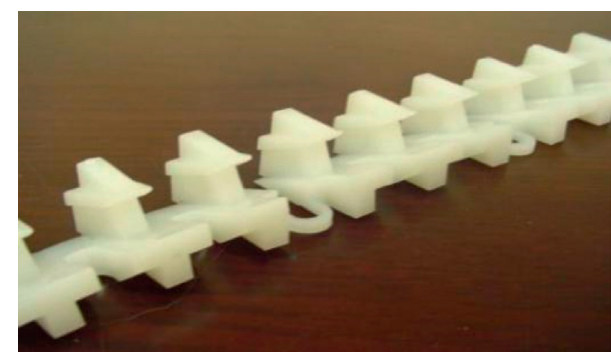

(b)

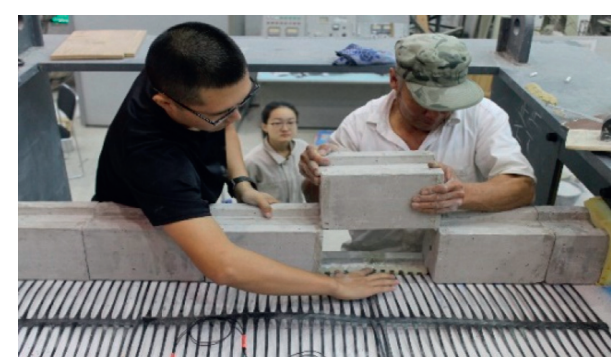

(d)

Figure 6: Connection between the geogrid and block: (a) schematic diagram, (b) plastic clasp, (c) geogrid and clasp, and (d) model construction.

(0.2-0.8\% and $4.5-4.9 \%)$ represented the transitional state from the quasielastic state to the plastic state and from the plastic state to the failure state, respectively. Li et al. [47] recommended $1.5 \%, 1.85 \%$, and $3.8 \%$ as the displacement indexes for seismic damage assessments of modular-block RSRWs. However, each displacement-controlling criterion is a conclusion drawn from limited test data and postearthquake investigations, and it is still unknown whether the findings are universal. With the wide application of reinforced soil structures, the correctness of this criterion will be verified by continuously accumulated data. Moreover, the method for applying the seismic evaluation criteria to the RSRW design is another point that requires investigation [34]. 


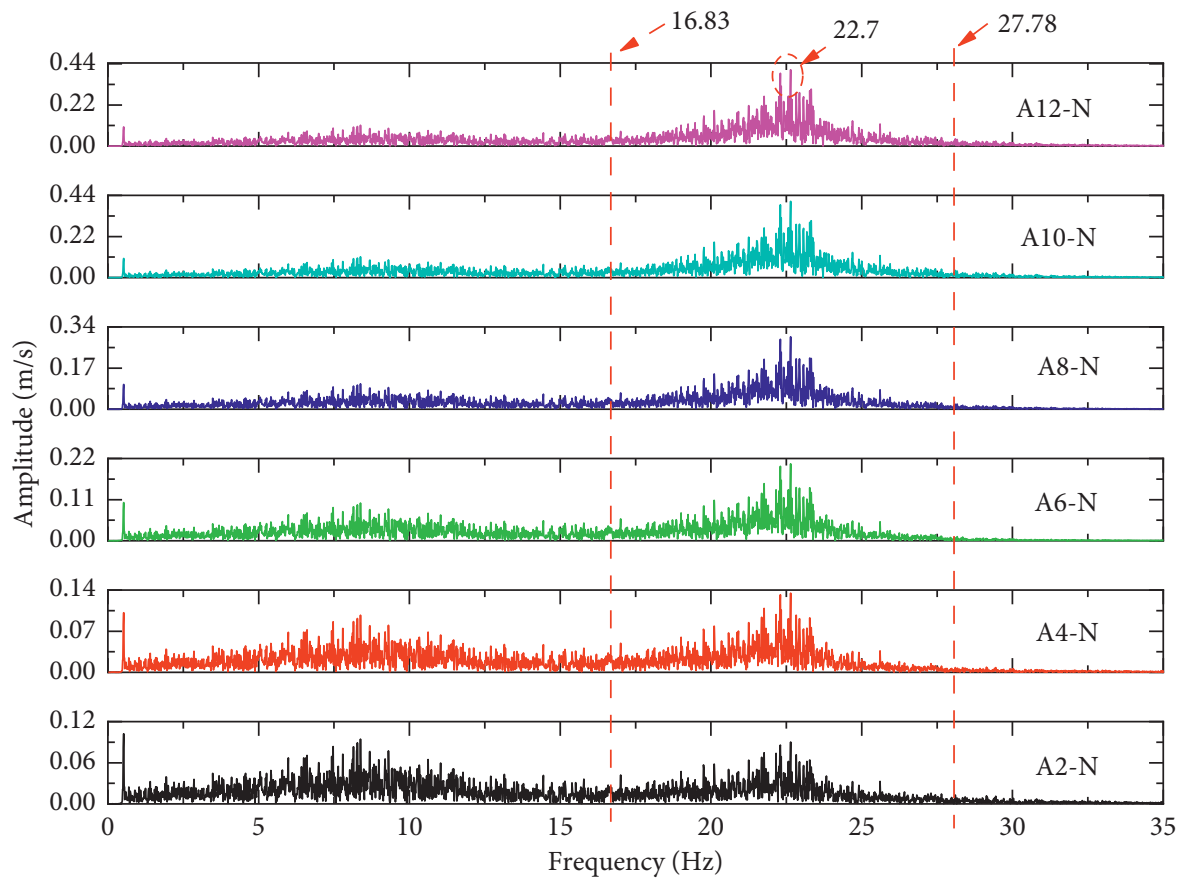

FIGURE 7: Free vibration Fourier spectra.

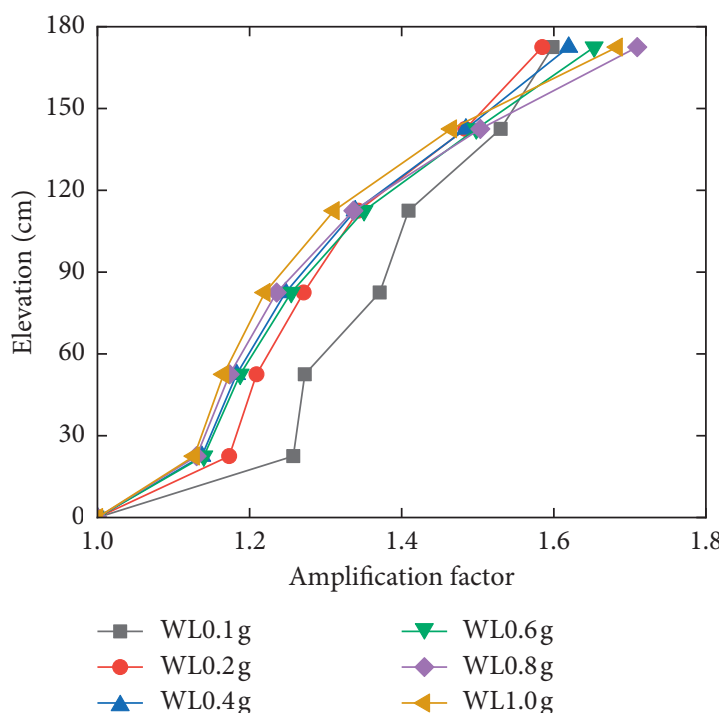

(a)

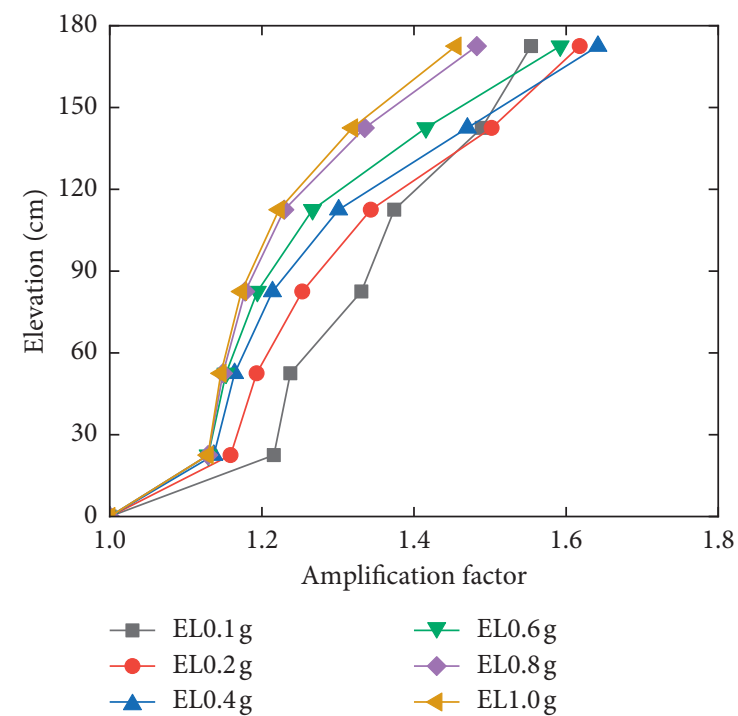

(b)

Figure 8: RMS amplification factor for the reinforced zone (scale factor: 1/4): (a) WL and (b) EL.

3.4. Backfill Surface Settlement. Settlement problems (such as excessive settlement and uneven settlement) have caused great issues for the application of geotechnical engineering. Figures 14 and 15 show the settlement distribution along the top surface of the RSRW. The recorded settlements are negligibly small (no more than $1 \mathrm{~mm}$ ) under the inputted acceleration not exceeding $0.4 \mathrm{~g}$. The positions near the face $(35 \mathrm{~cm})$ and the ends of the reinforcements $(140 \mathrm{~cm})$ exhibit larger settlement than the central position $(70 \mathrm{~cm}$ and $105 \mathrm{~cm}$ ) under the inputted acceleration exceeding $0.4 \mathrm{~g}$. The reason is that the face and backfill move toward the free face and cause larger settlement at a position near the face $(35 \mathrm{~cm})$, and no constraint of reinforcement causes larger settlement at the retaining zone area $(140 \mathrm{~cm})$. This conclusion is consistent with the model results reported by Ren et al. [7]. 


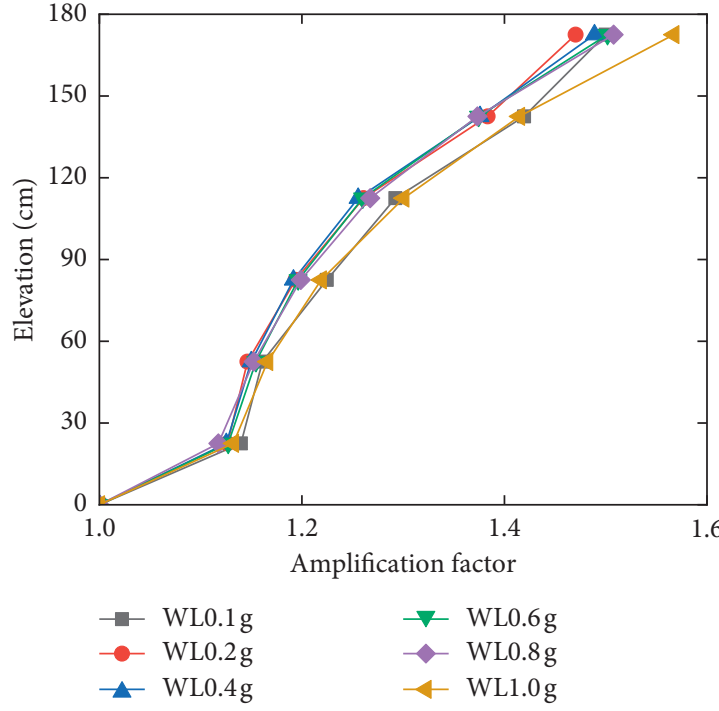

(a)

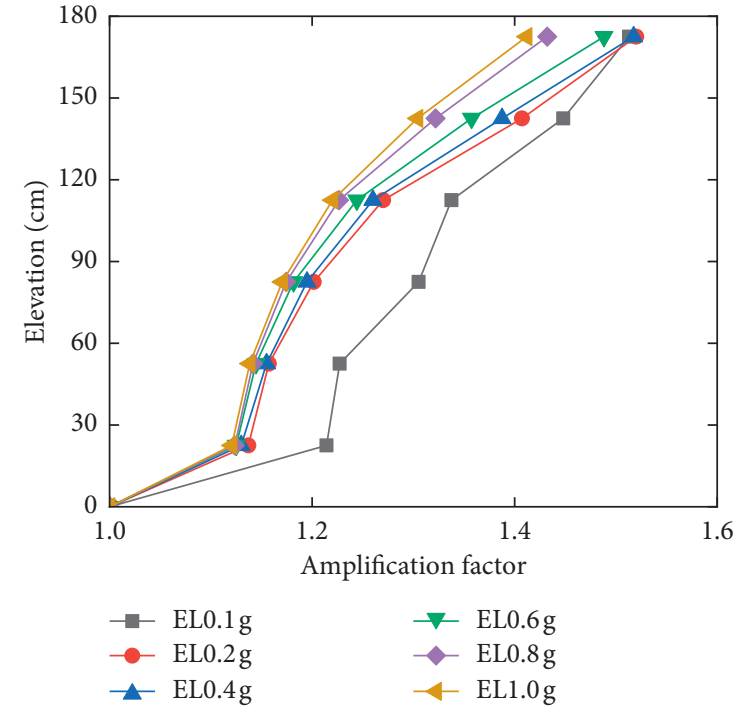

(b)

FiguRE 9: RMS amplification factor for the reinforced zone (scale factor: 1/2): (a) WL and (b) EL.

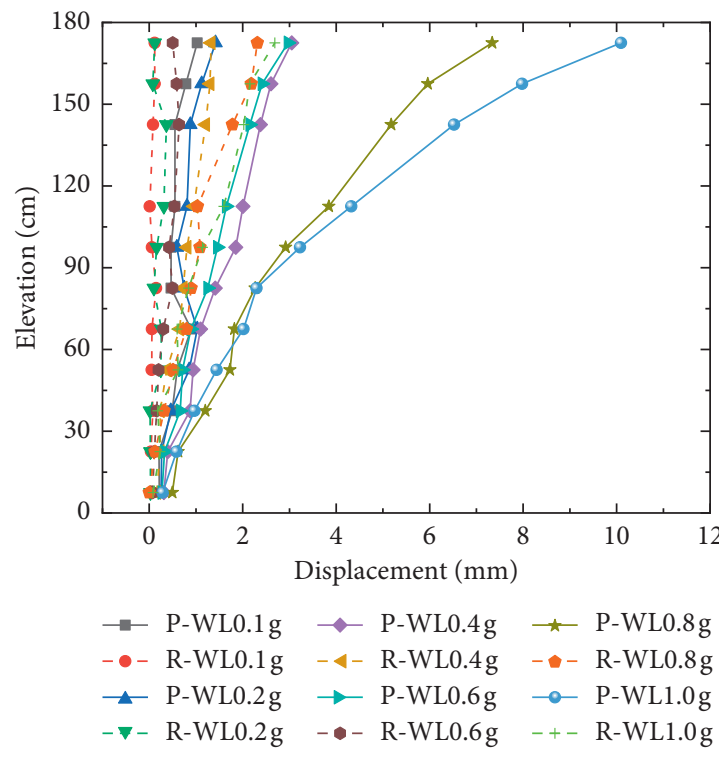

(a)

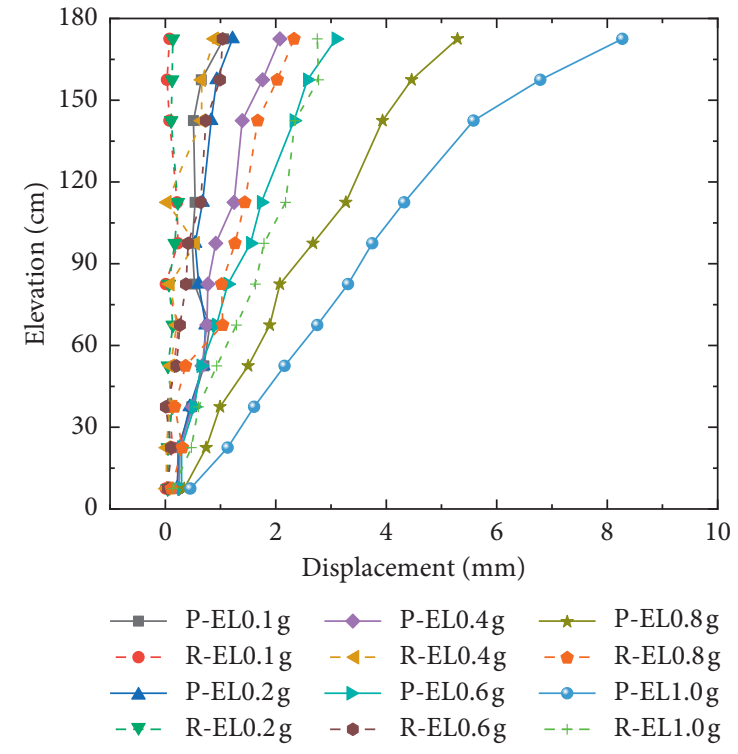

(b)

FIgURE 10: Lateral displacement distributions of the specimen (scale factor: 1/4): (a) WL and (b) EL.

3.5. Reinforcement Strains. The distributions of the measured peak tensile strain in the reinforcement layers for six instrumented sections of the specimen under earthquake motion with different waves and different scaling factors are shown in Figures 16 and 17. The results show that the incremental peak strains increase with increasing magnitude of peak acceleration in all reinforcement layers. The central layers $(F 3, F 5$, and $F 7)$ measured larger incremental peak strains than the bottom layers and the top layers, which is attributed to the central layers experiencing the largest peak force (such as dynamic soil pressure and seismic inertia force) during the earthquake waves. In practical engineering, it is recommended to use higher stiffness reinforcement in the central layers to prevent excessive deformation. Incremental peak strains near the face block connections are largest for layer one under the inputted acceleration not exceeding $0.4 \mathrm{~g}$. This is attributed to the limitations of the reinforcement near the connections caused by sliding toward the free face of the face blocks during shaking. The results are consistent with those of the sliding toe mode under acceleration not exceeding $0.4 \mathrm{~g}$ reported above, in which the sliding percentage is greater than that under an acceleration exceeding $0.4 \mathrm{~g}$. Moreover, the top four layers $(F 5, F 7, F 9$, and $F 11)$ occur at two local maximum points, 


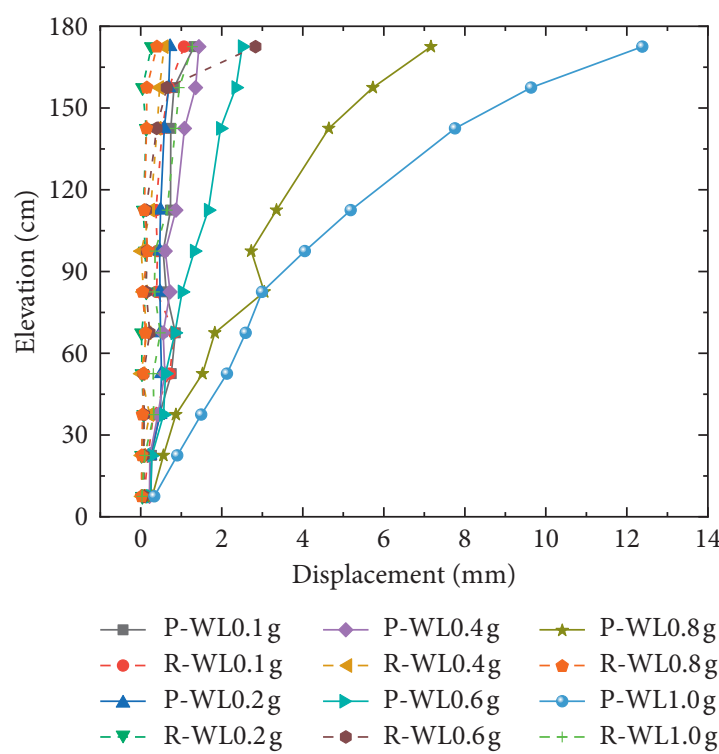

(a)

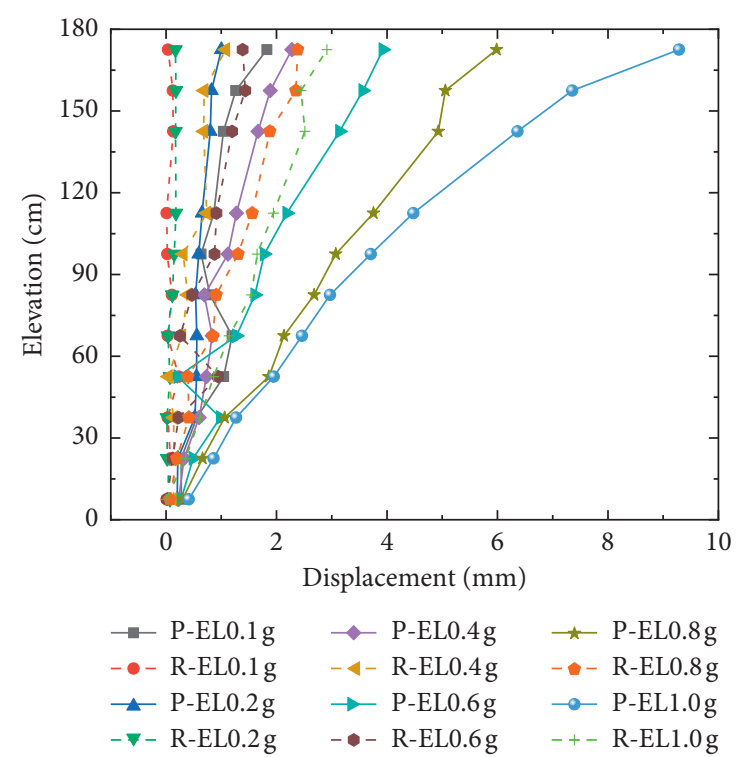

(b)

Figure 11: Lateral displacement distributions of the specimen (scale factor: 1/2): (a) WL and (b) EL.

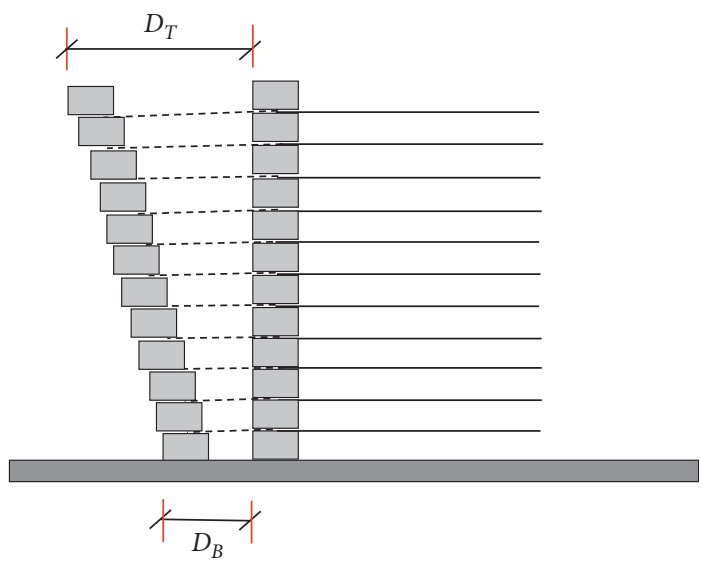

Figure 12: Sliding toe model.

which may be related to the existence of the two-wedge failure surface.

The maximum point of the internal stress of each layer of the RSRW is connected to obtain the potential failure surface of the backfill [19, 48]. FHWA [32] used the Rankine failure surface to calculate the extensible reinforcement and used the $0.3 \mathrm{H}$ bilinear failure surface $(\mathrm{H}$ is the height of the face wall) to calculate the inextensible reinforcement. The potential failure surface, linear surface, and $0.3 \mathrm{H}$ bilinear failure surface are also compared in Figures 16 and 17. The figures show that the trends of the potential failure surface are similar to those of the $0.3 \mathrm{H}$ bilinear failure surface, and they are not consistent with those of the linear surface. This is because the extensible property of the reinforcement is not developed due to the low incremental peak strains (less than $0.07 \%$ ) during seismic motions.
To establish the horizontal equilibrium equation for the geogrid between two adjacent strain gauges [25], the friction coefficient $\left(f_{\text {mob }}\right)$ between the geogrid and the backfill can be expressed as

$$
f_{\text {mob }}=\frac{\Delta T}{2 \sigma_{v}^{a} L_{b}},
$$

where $\Delta \mathrm{T}$ is the tensile load, which is the product of the difference in the strain of the geogrid and the geogrid tensile stiffness of two adjacent strain gauges, $\sigma_{v}$ is the vertical stress, a is the geogrid width, and $L_{b}$ is the distance between two adjacent strain gauges. According to Figure 16 and formula (3), the distribution of the friction coefficient under different loading cases for WL motion (scale factor: 1/4) is shown in Figure 18. The friction coefficient is nonlinearly distributed 


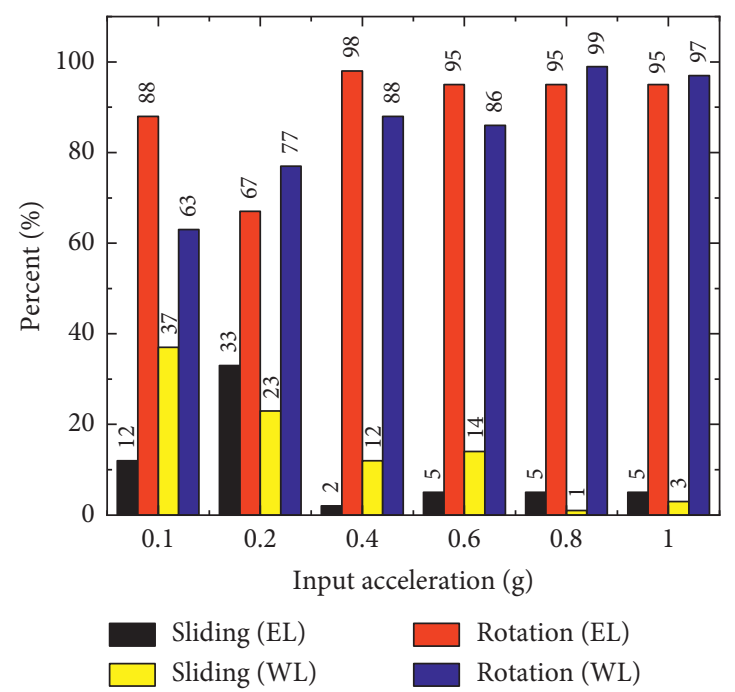

(a)

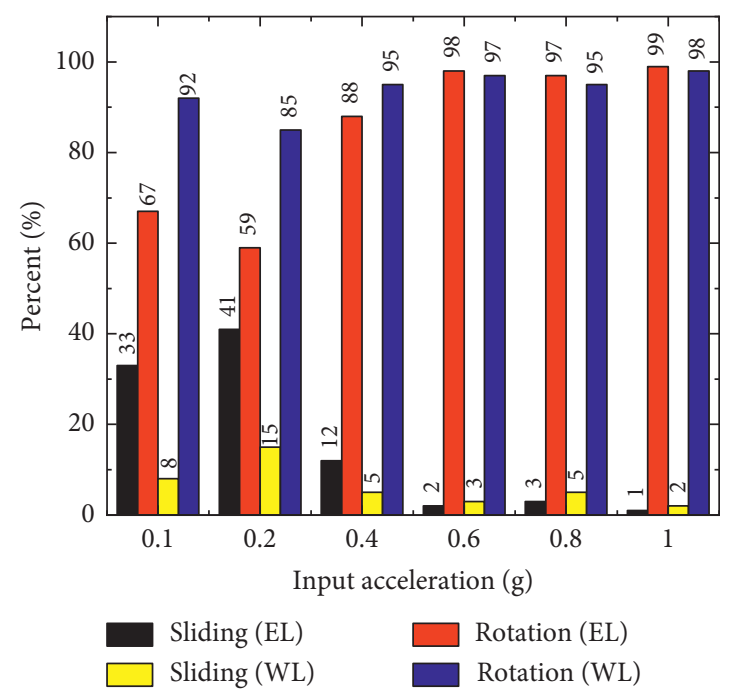

(b)

FIGURE 13: Sliding percentage and rotation percentage: (a) scale factor of $1 / 4$ and (b) scale factor of $1 / 2$.

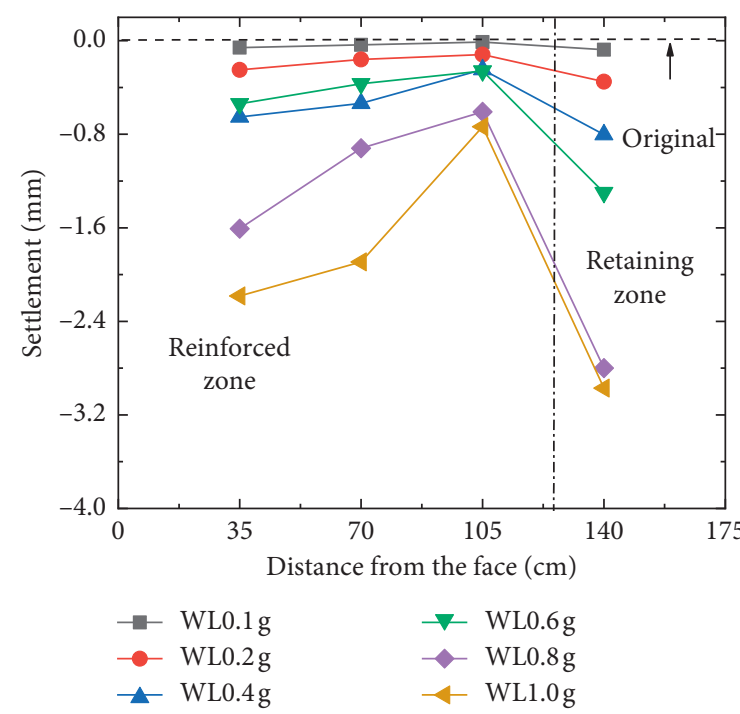

(a)

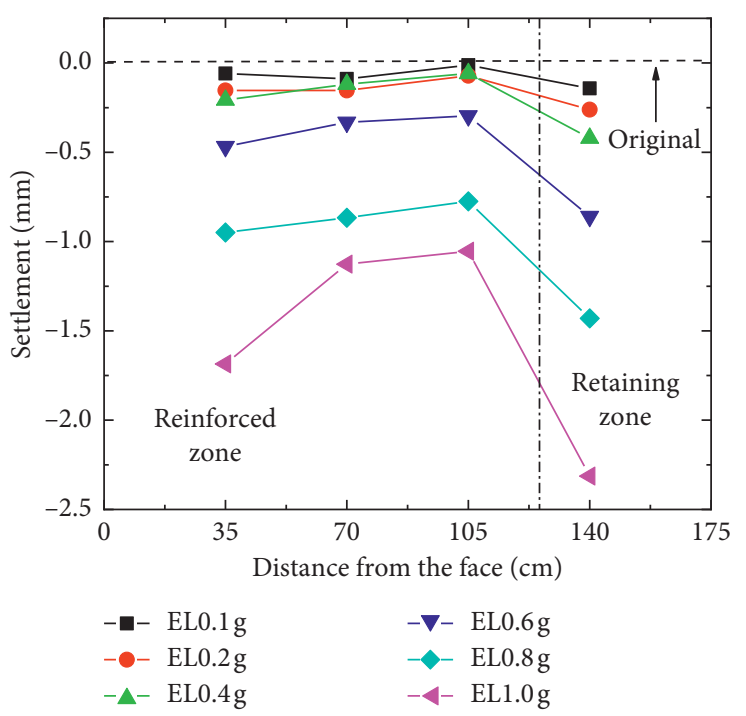

(b)

FIGURE 14: Settlement distributions of the specimen (scale factor: 1/4): (a) WL and (b) EL.

along with the reinforcements, and the friction coefficient of the top layer (F11) is the maximum. The friction coefficient of the bottom layer $(\mathrm{F} 1)$ is the minimum. This is attributed to the larger displacement of the top block and small vertical stress of the top reinforcement during shaking. The maximum friction coefficient is 0.18 when the inputted peak acceleration does not exceed $0.2 \mathrm{~g}$, which is less than the recommended value $(0.3-0.4)$ in the specification $[32,44]$. In addition, the reinforcement and the backfill move together. After the peak acceleration exceeds $0.2 \mathrm{~g}$, the maximum friction coefficient exceeds the recommended value (0.30.4 ), and the reinforcement and the backfill slide are relative to each other. This result is consistent with the peak displacement distribution of the specimen mentioned in Figure 10.

\section{Discussion}

The similarity relation of the materials in a reduced-scale model must always be considered. In this study, the measured strain of the geogrid is much smaller than the ultimate tensile strain, and the geogrid is not damaged, so the geogrid has not been scaled. The residual displacement of the model is much smaller than the predicted displacement of the 


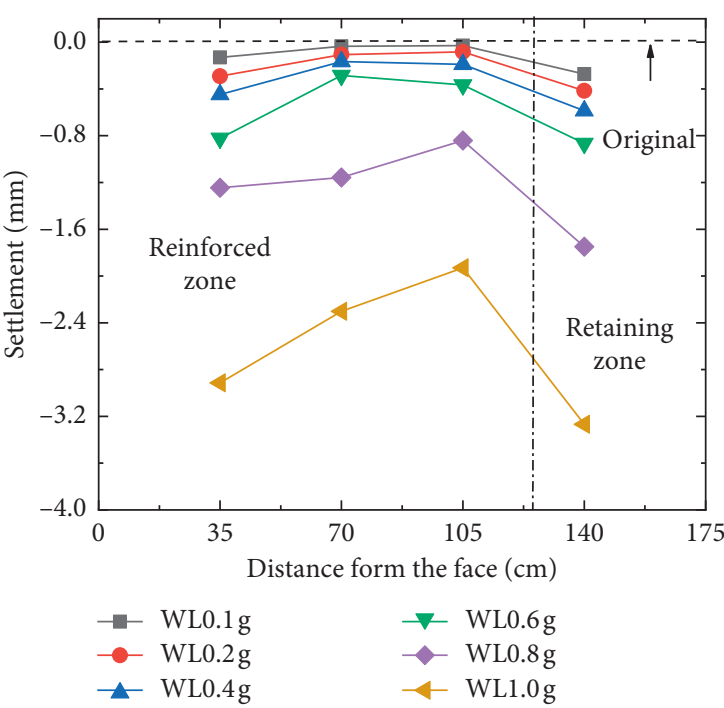

(a)

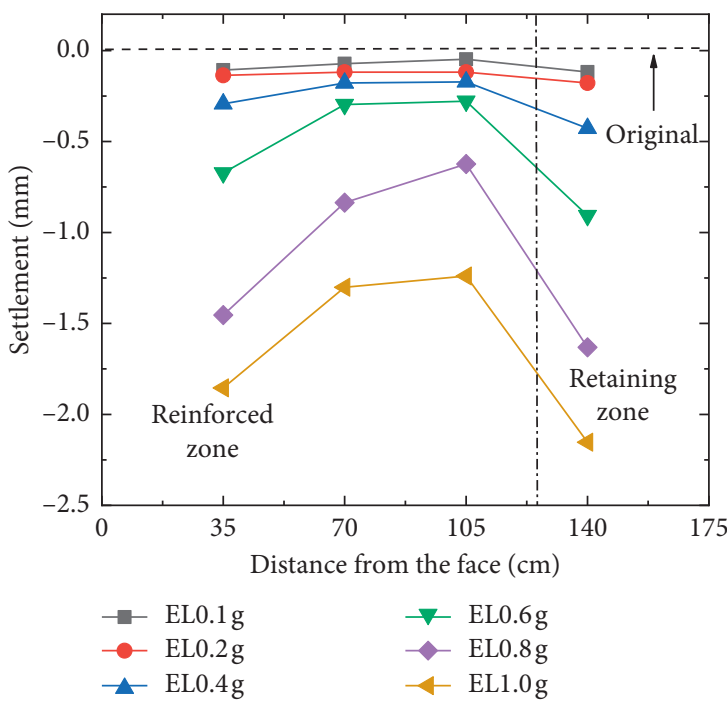

(b)

FIGURE 15: Settlement distributions of the specimen (scale factor: 1/2): (a) WL and (b) EL.

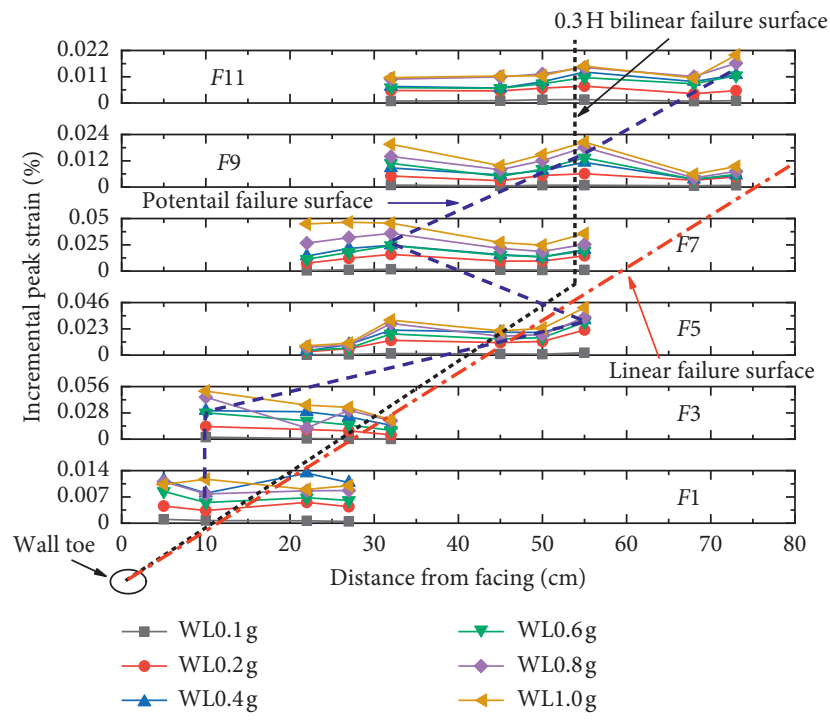

(a)

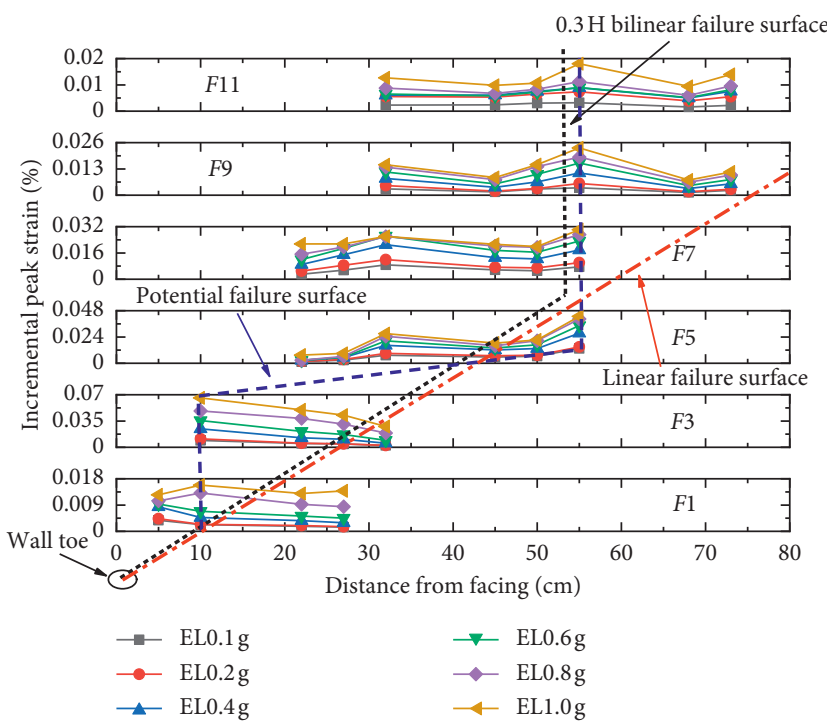

(b)

FIGURE 16: Distributions of the measured peak strain (scale factor: 1/4): (a) WL and (b) EL.

prototype RSRW under earthquake motion. The research results can be used as the results of RSRWs with higher stiffness geogrids. In addition, a few displacement calculation methods (such as the FHWA method, Geoservice method, and CTI method) [34, 49] use the reinforcement strain, reinforcement length, and wall height to calculate the displacement of the RSRW, which do not consider the influence of the blocks. FHWA [50] holds that panels are not structural members of geosynthetic reinforced soil integrated bridge systems and can only provide resistance to compaction. Therefore, the actual project size is adopted. The influence of the reinforcement strength and panel stiffness on the seismic response of RSRWs will be studied by numerical simulations in the future. 
$0.3 \mathrm{H}$ bilinear failure surface

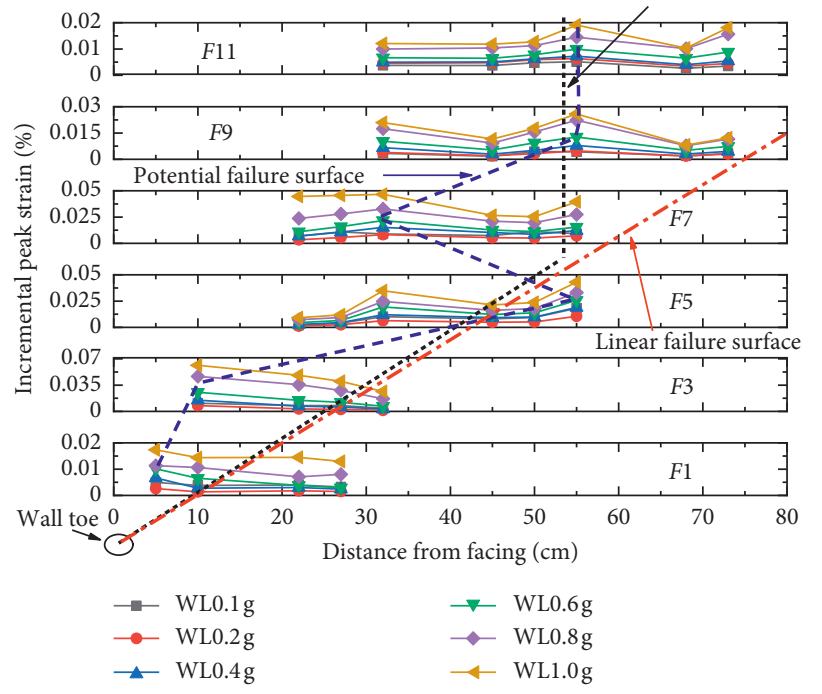

(a)

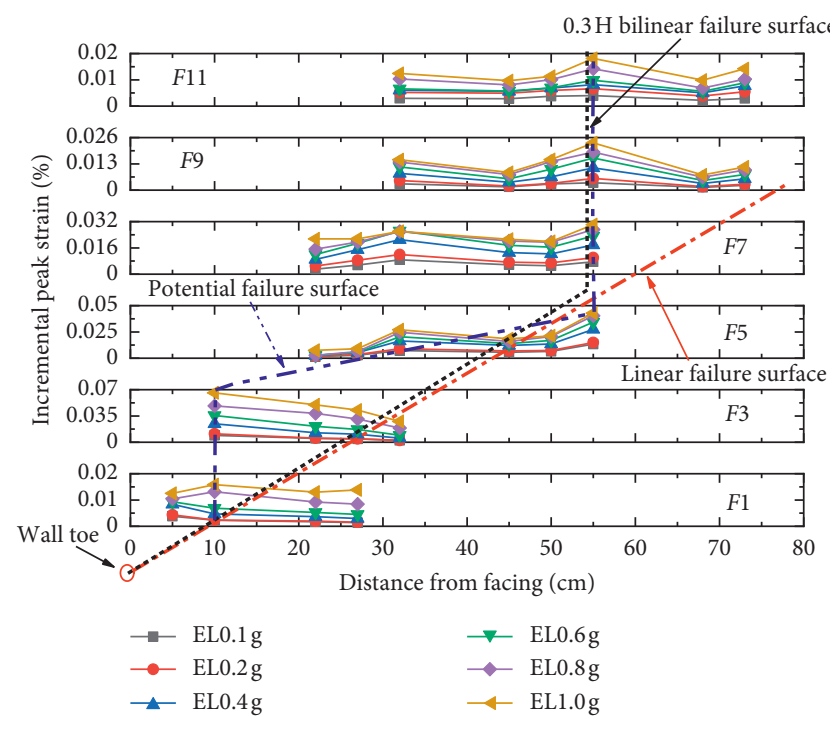

(b)

FIgURE 17: Distributions of the measured peak strain (scale factor: 1/2): (a) WL and (b) EL.

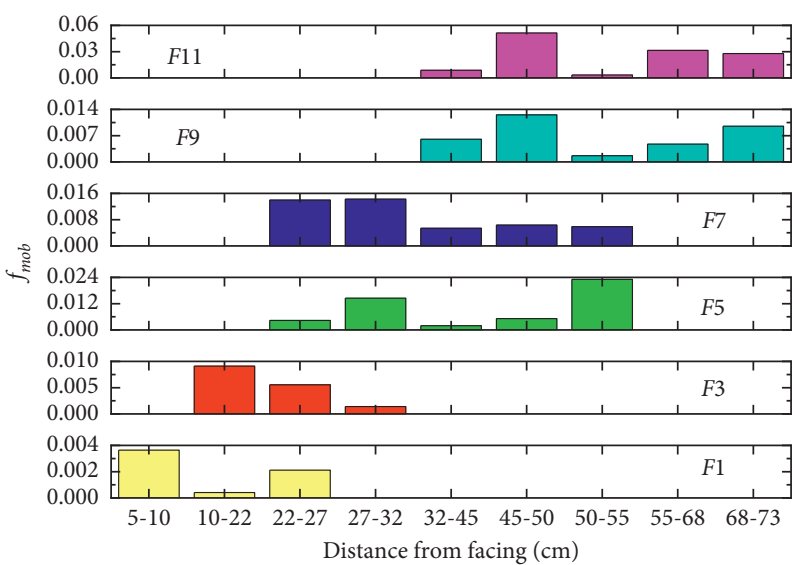

(a)

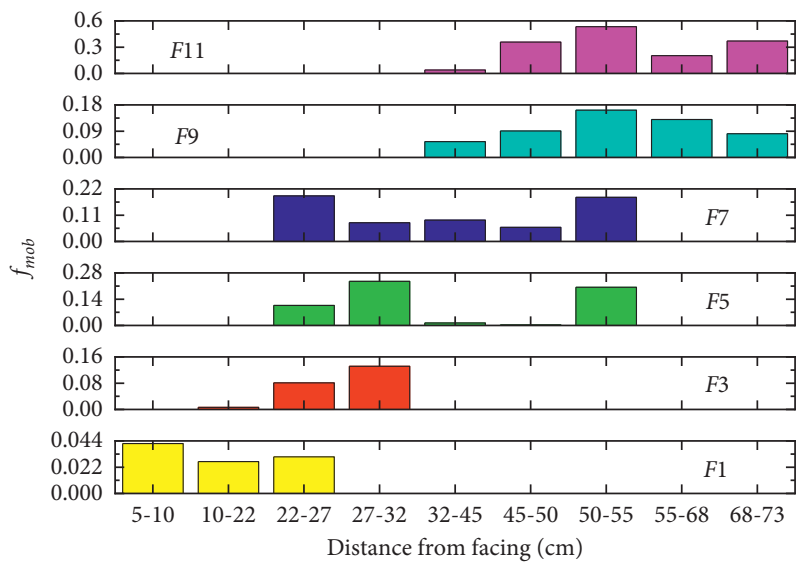

(c)

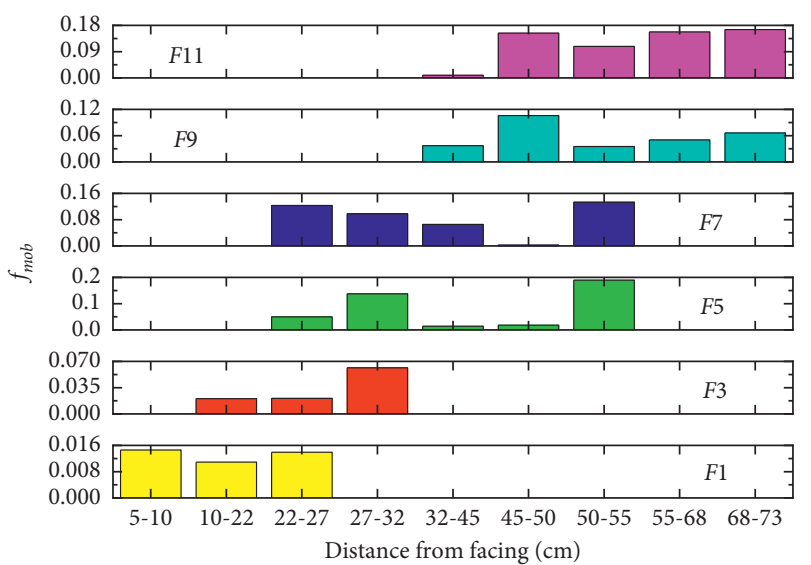

(b)

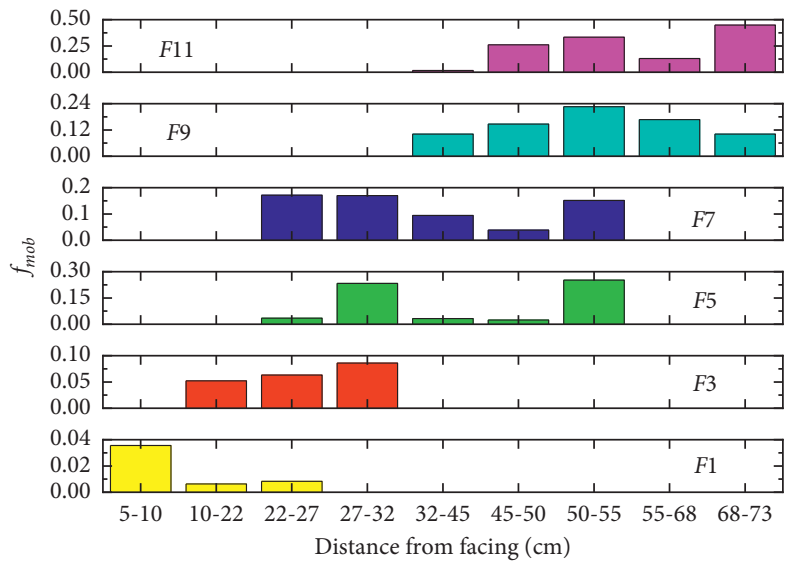

(d)

FIgURE 18: Continued. 


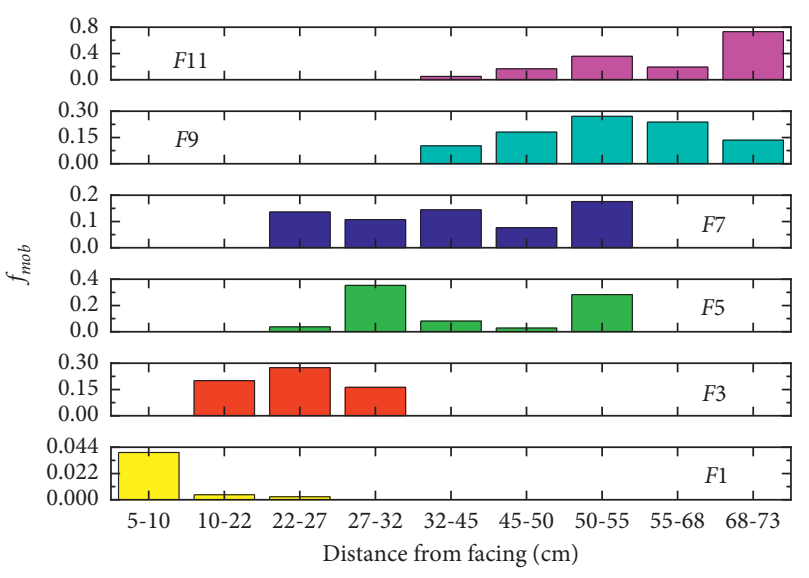

(e)

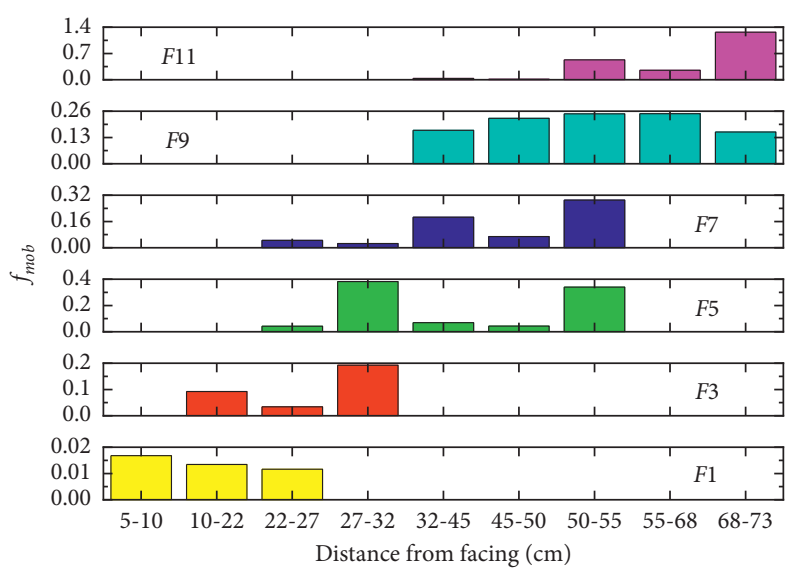

(f)

Figure 18: Graphs of the friction coefficients (scaled factor: 1/4): (a) WL 0.1 g, (b) WL $0.2 \mathrm{~g}$, (c) WL $0.4 \mathrm{~g}$, (d) WL $0.6 \mathrm{~g}$, (e) WL $0.8 \mathrm{~g}$, and (f) WL $1.0 \mathrm{~g}$.

\section{Conclusions}

This study has investigated the seismic performance of geogrid reinforced soil retaining walls using $1 \mathrm{~g}$ shaking table tests. For this purpose, the effect of earthquake motion and scale factors on the seismic behavior of this specimen with emphasis on the fundamental frequency, acceleration amplification, face displacement, backfill surface settlement, and reinforcement strains are investigated. The main conclusions can be summarized as follows:

(a) The fundamental frequency is in good agreement with the values predicted using the equation proposed by Richardson and Lee. Based on a comparison of the fundamental frequency of the prototype RSRW with the fundamental site frequency, it can be seen that resonance is not one of the key factors affecting the seismic performance of the RSRW.

(b) The RMS acceleration amplification factors increased nonlinearly with the wall height and decreased with increasing seismic loading. However, the acceleration amplification factor is regarded as a constant factor in a few codes, which is not consistent with the seismic performance of RSRWs.

(c) The distributions of the residual displacement are similar to that of the peak displacement, which generally increase with the wall height and seismic motion, and the highest values are measured at the top block. The maximum values during peak acceleration are partially recovered at the end of shaking. The combination of sliding and rotation is observed as the predominant mode of displacement. The sliding percentage decreases and the rotation percentage increases as the input acceleration increases, and the rotation percentage dominates the displacement mode of the specimen.

(d) The measured values of the settlement are negligibly small when the inputted acceleration does not exceed $0.4 \mathrm{~g}$. The positions near the face $(35 \mathrm{~cm})$ and the ends of the reinforcement $(140 \mathrm{~cm})$ record larger settlement than that at the central position $(70 \mathrm{~cm}$ and $105 \mathrm{~cm}$ ) when the inputted acceleration exceeds $0.4 \mathrm{~g}$.

(e) The recorded values of the strain in the reinforcement increase with increasing magnitude of the peak acceleration and maximum values measured at the central layers. The data indicate that reinforcement with a higher stiffness need to be laid in the central layers to prevent excessive deformation. The trends of the potential failure surface are similar to those of the $0.3 \mathrm{H}$ bilinear failure surface due to the lower incremental peak strains (less than 0.07\%) during seismic motions. The friction coefficient is nonlinearly distributed along with the reinforcements, and the maximum friction coefficient appears at the top layer (F11). The maximum friction coefficient under the inputted peak acceleration that does not exceed $0.2 \mathrm{~g}$ is less than the recommended value (0.3$0.4)$ in the specification. After the peak acceleration exceeds $0.2 \mathrm{~g}$, the maximum friction coefficient exceeds the recommended value (0.3-0.4).

\section{Data Availability}

The original data used to support the findings of this study are included within the article.

\section{Conflicts of Interest}

The authors declare that they have no conflicts of interest.

\section{Authors' Contributions}

Xiaoguang Cai reviewed and edited the manuscript. Sihan Li wrote the original draft of the manuscript. Xin Huang performed formal analysis. Chen Zhu investigated the study. 
Liping Jing supervised the study. Xiaoguang Cai involved in project administration. Xiaoguang Cai and Honglu Xu acquired fund.

\section{Acknowledgments}

The authors would like to thank the anonymous reviewers of this study for their incisive comments that improved its quality. This research was funded by the Earthquake Technology Spark Program of China (XH204402), the Fundamental Research Funds for the Central Universities (ZY20215107), and the National Natural Science Foundation of China (51778144).

\section{References}

[1] J. Han, Y. Jiang, and C. Xu, "Recent advances in geosyntheticreinforced retaining walls for highway applications," Frontiers of Structural and Civil Engineering, vol. 12, no. 2, pp. 239-247, 2017.

[2] M. Yazdandoust, "Investigation on the seismic performance of steel-strip reinforced-soil retaining walls using shaking table test," Soil Dynamics and Earthquake Engineering, vol. 97, pp. 216-232, 2017.

[3] C. Fan, H. Liu, J. Cao, and H. I. Ling, "Responses of reinforced soil retaining walls subjected to horizontal and vertical seismic loadings," Soil Dynamics and Earthquake Engineering, vol. 129, Article ID 105969, 2020.

[4] H. I. Ling, D. Leshchinsky, and N. N. S. Chou, "Post-earthquake investigation on several geosynthetic-reinforced soil retaining walls and slopes during the Ji-Ji earthquake of Taiwan," Soil Dynamics and Earthquake Engineering, vol. 21, no. 4, pp. 297-313, 2001.

[5] J. Koseki, "Use of geosynthetics to improve seismic performance of earth structures," Geotextiles and Geomembranes, vol. 34, pp. 51-68, 2012.

[6] J. Kuwano, Y. Miyata, and J. Koseki, "Performance of reinforced soil walls during the 2011 Tohoku earthquake," Geosynthetics International. 2014, vol. 21, no. 3, pp. 179-196, 2014.

[7] F. Ren, Q. Huang, and G. Wang, "Shaking table tests on reinforced soil retaining walls subjected to the combined effects of rainfall and earthquakes," Engineering Geology, vol. 267, Article ID 105475, 2020.

[8] J. Koseki, R. J. Bathurst, E. Guler, and J. Kuwano, "Seismic stability of reinforced soil walls, Invited keynote paper," in Proceedings of the 8th International Conference of Geosynthetics, p. 28, Yokohama, Japan, September 2006.

[9] K. Rollins, C. Ledezma, and G. Montalva, Geotechnical Aspects of April 1, 2014, M8.2 iquique, Chile Earthquake, Geotechnical Extreme Events Reconnaissance (Geer) Association, Austin, TX, USA, 2014.

[10] R. D. Holtz, "Geosynthetic reinforced soil: from the experimental to the familiar," Journal of Geotechnical and Geoenvironmental Engineering, vol. 143, no. 9, Article ID 03117001, 2017.

[11] J. J. Zhang, J. Feng, S. G. Xiao, and C. Liu, "Discussions on two key technical problems for seismic design of retaining structures," Journal of Southwest Jiaotong University, vol. 44, no. 3, pp. 321-326, 2009.

[12] H. I. Ling, "Chapter 25. A critical review of full-scale shaking table tests conducted on reinforced soil retaining walls," Reinforced Soil Engineering: Advances in Research and
Practice, pp. 491-510, Marcel Dekker, New York, NY, USA, 2003.

[13] H. I. Ling, Y. Mohri, D. Leshchinsky, C. Burke, K. Matsushima, and H. Liu, "Large-scale shaking table tests on modular-block reinforced soil retaining walls," Journal of Geotechnical and Geoenvironmental Engineering, vol. 131, no. 4, pp. 465-476, 2005.

[14] A. C. Sander, P. J. Fox, and A. Elgamal, "Full-scale seismic test of MSE retaining wall at UCSD," in Proceedings of the GeoCongress 2014 Technical Papers, February 2014.

[15] M. M. El-Emam and R. J. Bathurst, "Facing contribution to seismic response of reduced-scale reinforced soil walls," Geosynthetics International, vol. 12, no. 5, pp. 215-238, 2005.

[16] F. Tatsuoka, D. Hirakawa, M. Nojiri et al., "A new type of integral bridge comprising geosynthetic-reinforced soil walls," Geosynthetics International, vol. 16, no. 4, pp. 301-326, 2009.

[17] F. Tatsuoka, H. Muñoz, T. Kuroda et al., "Stability of existing bridges improved by structural integration and nailing," Soils and Foundations, vol. 52, no. 3, pp. 430-448, 2012.

[18] A. M. Krishna and G. M. Latha, "Modeling the dynamic response of wrap-faced reinforced soil retaining walls," International Journal of Geomechanics, vol. 12, no. 4, pp. 439450, 2012.

[19] E. Guler and O. Selek, "Reduced-scale shaking table tests on geosynthetic reinforced soil walls with modular facing," Journal of Geotechnical and Geoenvironmental Engineering, vol. 140, no. 6, Article ID 04014015, 2014.

[20] L. Wang, G. Chen, and S. Chen, "Experimental study on seismic response of geogrid reinforced rigid retaining walls with saturated backfill sand," Geotextiles and Geomembranes, vol. 43, no. 1, pp. 35-45, 2015.

[21] L.-C. Cao, X. Fu, Z.-J. Wang, Y.-Y. Zhou, F.-C. Liu, and J.-J. Zhang, "Seismic responses of the steel-strip reinforced soil retaining wall with full-height rigid facing from shaking table test," Journal of Mountain Science, vol. 15, no. 5, pp. 1137-1152, 2018.

[22] X. G. Cai, S. H. Li, and X. Huang, "Shaking table tests on dynamic characteristics of two-stage reinforced soil retaining wall," China Journal of Highway and Transport, vol. 31, no. 2, pp. 200-207, 2018.

[23] X. G. Cai, S. H. Li, and X. Huang, "Geogrid strain and failure surface of two-stage reinforced soil retaining wall under horizontal seismic loading," Chinese Journal of Geotechnical Engineering, vol. 40, no. 8, pp. 1528-1534, 2018.

[24] Y. W. Zheng, J. S. McCartney, P. B. Shing, and P. Fox, "Physical model tests of half-scale geosynthetic reinforced soil bridge abutments. II: dynamic Loading," Journal of Geotechnical and Geoenvironmental Engineering, vol. 145, no. 11, Article ID 04019095, 2019.

[25] P. Xu, K. Hatami, and G. Jiang, "Shaking table study of the influence of facing on reinforced soil wall connection loads," Geosynthetics International, vol. 27, no. 4, pp. 364-378, 2020.

[26] R. J. Bathurst and K. Hatami, "Seismic response analysis of a geosynthetic-reinforced soil retaining wall," Geosynthetics International, vol. 5, no. 1-2, pp. 127-166, 1998.

[27] K. Hatami and R. J. Bathurst, "Effect of structural design on fundamental frequency of reinforced-soil retaining walls," Soil Dynamics and Earthquake Engineering, vol. 19, no. 3, pp. 137-157, 2000.

[28] H. Liu, X. Wang, and E. Song, "Reinforcement load and deformation mode of geosynthetic-reinforced soil walls subject to seismic loading during service life," Geotextiles and Geomembranes, vol. 29, no. 1, pp. 1-16, 2011. 
[29] H. Liu, C. Hung, and J. Cao, "Relationship between Arias intensity and the responses of reinforced soil retaining walls subjected to near-field ground motions," Soil Dynamics and Earthquake Engineering, vol. 111, pp. 160-168, 2018.

[30] F. Ren, F. Zhang, C. Xu, and G. Wang, "Seismic evaluation of reinforced-soil segmental retaining walls," Geotextiles and Geomembranes, vol. 44, no. 4, pp. 604-614, 2016.

[31] Y. L. Lin, Chapter 5. research on seismic behaviors of geotechnical structures and seismic earth pressure, $\mathrm{PhD}$ thesis, Central South University, Changsha, China, 2011.

[32] Fhwa (Federal Highway Administration), "Chapter 7: design of mse walls for extreme events," in Design and Construction of Mechanically Stabilized Earth Walls and Reinforced Soil Slopes, R. R. Berg, B. R. Christopher, and N. C. Samtani, Eds., FHWA-NHI-10-024, Washington, DC, 2009.

[33] M. El-Emam, "Behavior of reinforced soil walls under earthquake loading," PhD Dissertation, Queen's University, Kingston, Canada, 2003.

[34] S. H. Li, X. G. Cai, L. P. Jing et al., "Research progress on deformation characteristics of reinforced soil retaining wall," World Earthquake Engineering, vol. 35, no. 4, pp. 114-124, 2019.

[35] S. Iai, "Similitude for shaking table tests on soil-structure-fluid model in 1g gravitational field," Soils and Foundations, vol. 29, no. 1, pp. 105-118, 1989.

[36] R. J. Bathurst, T. M. Allen, and D. L. Walters, "Short-term strain and deformation behavior of geosynthetic walls at working stress conditions," Geosynthetics International, vol. 9, no. 5-6, pp. 451-482, 2002.

[37] ASTM, Standard Test Method for Determining Tensile Properties of Geogrids by the Single or Multi-Rib Tensile Method, ASTM, West Conshohocken, PA, USA, 2015.

[38] T. M. Allen and R. J. Bathurst, "Geosynthetic reinforcement stiffness characterization for MSE wall design," Geosynthetics International, vol. 26, no. 6, pp. 592-610, 2019.

[39] Ministry of Housing and Urban-Rural Development of the People's Republic of China, Chapter 5: Earthquake Action and Aseismic Checking Procedure, Code For Seismic Design of Buildings, China Architecture and Building Press, Beijing, China, 2010.

[40] S. Grasso, M. R. Massimino, and M. S. V. Sammito, "New stress reduction factor for evaluating soil liquefaction in the coastal area of catania (Italy)," Geosciences, vol. 11, no. 1, p. 12, 2021.

[41] F. Castelli, A. Cavallaro, A. Ferraro, and S. Grasso, "In situ and laboratory tests for site response analysis in the ancient city of Noto (Italy)," in Proceedings of the 1st IMEKO TC4 International Workshop on Metrology for Geotechnics, pp. 85-90, Benevento, Italy, 17-18 March 2016.

[42] A. Ferraro, S. Grasso, and M. R. Massimino, "Site effects evaluation in Catania (Italy) by means of 1-D numerical analysis," Annales Geophysicae, vol. 61, p. SE224, 2018.

[43] S. Li, X. Cai, H. Xu, L. Jing, X. Huang, and C. Zhu, "Dynamic behaviour of reinforced soil retaining wall under horizontal seismic loading," IOP Conference Series: Earth and Environmental Science, vol. 569, Article ID 012001, 2020.

[44] Ministry of Railways of the People's Republic of China, Chapter 3: Subgrade and Retaining Wall, Chinese Code for Seismic Design of Railway Engineering, China Plan Press, Beijing, China, 2006.

[45] C.-C. Huang, S.-H. Wu, and H.-J. Wu, "Seismic displacement criterion for soil retaining walls based on soil strength mobilization," Journal of Geotechnical and Geoenvironmental Engineering, vol. 135, no. 1, pp. 74-83, 2009.
[46] J. J. Zhang and P. F. Han, "Displacement based seismic design method for gravity retaining walls-Large scale shaking table tests," Chinese Journal of Geotechnical Engineering, vol. 34, no. 3, pp. 417-423, 2012.

[47] S. Li, X. Cai, L. Jing, H. Xu, X. Huang, and C. Zhu, "Lateral displacement control of modular-block reinforced soil retaining walls under horizontal seismic loading," Soil Dynamics and Earthquake Engineering, vol. 141, Article ID 106485, 2021.

[48] S. Li, X. Cai, L. Jing, H. Xu, X. Huang, and C. Zhu, "Reinforcement strain and potential failure surface of geogrid reinforced soil-retaining wall under horizontal seismic loading," Shock and Vibration, vol. 2020, Article ID 8864256, 17 pages, 2020.

[49] K. Mshsa, X. Ming, Q. Tong, and Q. Jennifer, "Evaluation of prediction methods for lateral deformation of GRS walls and abutments," Journal of Geotechnical and Geoenvironmental Engineering, vol. 143, no. 2, pp. 81-89, 2020.

[50] Z. Ellis, Geosynthetic Reinforced Soil Integrated Bridge System Interim Implementation Guide Publication No. FHWA-HRT11-026, (Federal Highway Administration) (Brief Article). Public Roads, Washington, DC, 2011. 